\title{
DENDROLOŠKE ZNAČAJKE ARBORETUMA TRSTENO
}

\section{DENDROLOGICAL CHARACTERISTICS OF THE TRSTENO ARBORETUM}

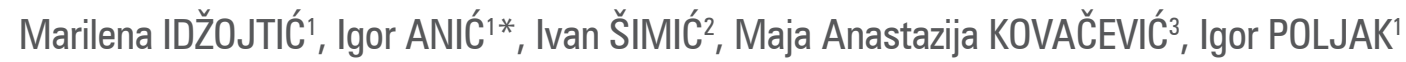

\begin{abstract}
SAŽETAK
Arboretum Trsteno je povijesni ladanjski posjed s perivojima, starim maslinicima i prirodnom vegetacijom, kojim upravlja Hrvatska akademija znanosti i umjetnosti. Povijest ladanjske cjeline može se pratiti od 1494. godine, a Arboretum površine 28 ha osnovan je 1948. godine. Radi utvrđivanja sadašnjega bogatstva drvenastih svojti, biljke su determinirane tijekom 2017. i 2018. godine. Napravljena je dendrološka analiza te je učinjena usporedba sadašnjega bogatstva dendroflore u odnosu na literaturne podatke dostupne iz sredine i kraja prošloga, kao i početka ovoga stoljeća. U Arboretumu Trsteno sada raste 317 drvenastih svojti, od čega je 233 vrsta, 8 podvrsta, 2 varijeteta, 10 križanaca i 64 kultivara. Svojte pripadaju u 179 različitih rodova iz 82 porodice. Golosjemenjača je 19 svojti, a kritosjemenjača 298 svojti. Svojti autohtonih u Hrvatskoj je 84, odnosno 26 \%, a među njima prevladavaju mediteranske biljke. Od egzotičnih vrsta i podvrsta, odnosno onih koje rastu isključivo izvan europskoga kontinenta, najviše je azijskih vrsta (64), zatim slijede vrste s područja Amerike (45 vrsta), Afrike (14 vrsta) i Australije (6 vrsta). Jedinstvene ili vrlo rijetko prisutne svojte u Hrvatskoj su npr. Acacia cyclops A. Cunn. ex G. Don, A. karoo Hayne, Albizia amara (Roxb.) B. Boivin, Callitris preisii Miq., Casuarina cunninghamiana Miq., Persea indica (L.) Spreng., Retama sphaerocarpa Raf., Schinus weinmannifolius Engl. i Vitex negundo var. heterophylla (Franch.) Rehder. Od prvog popisa biljaka prije 65 godina do danas u Arboretum su unošene nove svojte. Ukupan broj svojti povećan je s 226 na 317. Tome je znantno pridonijelo obogaćanje zbirki pojedinih rodova, ali također i revizije prijašnjih determinacija koje su donijele na svjetlo brojne stare kultivare, kao npr. rodova Olea, Citrus, Aloe, Pelargonium i dr. Svojti koje su se od popisa 1953. godine do danas zadržale u Arboretumu je 148, što znači da je od današnjih 317 svojti nešto manje od pola bilo u Arboretumu i prije 65 godina. To je posljedica djelovanja niza čimbenika, uključujući klimu, uvjete uzgoja, požare, ali i bolesti i štetnike. Egzotične biljke toplih područja drugih kontinenata uglavnom su dobro prilagođene na stanišne uvjete u Arboretumu, međutim, povremeno stradaju od ekstremno niskih temperatura koje traju više dana. Arboretum Trsteno jedini je naš arboretum koji je pod upravom znanstvene institucije - Hrvatske akademije znanosti i umjetnosti te ispunjava zadatke postavljene pred povijesni arboretum u suvremenom svijetu.
\end{abstract}

KLJUČNE RIJEČI: Arboretum Trsteno, Hrvatska, Mediteran, drveće, grmlje, polugrmovi, dendrološka analiza

\section{UVOD}

\section{INTRODUCTION}

Arboretum Hrvatske akademije znanosti i umjetnosti u Trstenom ili kraće Arboretum Trsteno, naziv je za arhitektonsku cjelinu povijesnoga ladanjskog posjeda s perivojima, starim maslinicima i površinama pod prirodnom vegetacijom. Perivoj u Trstenom je 1948. godine proglašen zaštićenom prirodnom rijetkošću. Iste godine je osnovan Arboretum - stanica za introdukciju stranih vrsta drveća i grmlja u sastavu Ministarstva šumarstva FNRJ. Arboretum je 1951.

\footnotetext{
1 Prof. dr. sc. Marilena Idžojtić, midzojtic@sumfak.hr; akademik Igor Anić, ianic@sumfak.hr; doc. dr. sc. Igor Poljak, ipoljak@sumfak.hr; Sveučilište u Zagrebu Šumarski faultet, Svetošimunska 23, 10000 Zagreb

2 Dr. sc. Ivan Šimić, arbor@hazu.hr, Hrvatska akademija znanosti i umjetnosti, Arboretum Trsteno, Potok 20, Trsteno, 20235 Zaton Veliki

${ }^{3}$ Dr. sc. Maja Anastazija Kovačević, cannosana@yahoo.com, Potok 15, Trsteno, 20235 Zaton Veliki

*Korespondencija: akademik Igor Anić, ianic@sumfak.hr
} 
godine predan Jugoslavenskoj akademiji znanosti i umjetnosti u Zagrebu (danas HAZU). Od 1962. godine Arboretum Trsteno ima svojstvo zaštićenog objekta prirode kao spomenik prirode/spomenik vrtne arhitekture - arboretum, te je upisan u registar zaštićenih objekata prirode. Godine 1967. utvrđuje se da ljetnikovac Gučetić - Gozze u Trstenom ima svojstvo spomenika kulture te se upisuje u registar nepokretnih spomenika kulture. U članku 235. Zakona o zaštiti prirode (NN 80/13) piše da zaštitu i upravljanje Arboretumom Trsteno nastavlja provoditi Hrvatska akademija znanosti i umjetnosti sukladno Zakonu o Hrvatskoj akademiji znanosti i umjetnosti (NN 65/09), uz odgovarajuću primjenu ovoga Zakona. Uprava za zaštitu kulturne baštine Ministarstva kulture Republike Hrvatske 2017. godine donijela je Rješenje kojim Ladanjska cjelina obitelji Gozze i Arboretum Trsteno imaju svojstvo kulturnog dobra, a sve prema Zakonu o zaštiti i očuvanju kulturnih dobara (NN 44/17).

Povijest ladanjske cjeline u Trstenome počinje izgradnjom perivoja Gučetićeva ljetnikovca u razdoblju od 1494. do 1502. godine. Njegovo značenje Šćitaroci i Kovačević (2014) opisuju činjenicom kako je to "jedini sačuvani dubrovački perivoj čiji je razvoj u pet proteklih stoljeća tekao evolucijskim rastom tijekom stilskih etapa i prostornoga širenja na veću površinu. Od jednostavne, ranorenesansne kompozicije dubrovačkoga perivoja u kasnorenesansnoj i baroknoj etapi razvija se izrazita jednoosna koncepcija, koja se kao prepoznatljiva osebujnost zadržala do danas." Istraživanjima je utvrđen vremenski slijed njegovih vlasnika od početka izgradnje 1494. godine do danas, koji je pokazao izmjenu 14 vlasnika Gučetića do današnjega vlasnika Hrvatske akademije znanosti i umjetnosti. Ladanjski posjed Gozze neposredno nakon Drugog svjetskog rata je prešao iz privatnog u državno vlasništvo eksproprijacijom. Nakon stavljanja pod upravu današnje Hrvatske akademije znanosti i umjetnosti u Zagrebu, ladanjska cjelina se prenamjenjuje. Osniva se Arboretum, perivoj i ljetnikovac se otvaraju posjetiteljima, a na dijelu poljodjelskih površina počinju znanstvena istraživanja poljoprivrede i šumarstva. Akademija za prvog voditelja Arboretuma Trsteno imenuje šumarskoga stručnjaka, akademika Aleksandra Ugrenovića, koji 1953. godine izdaje monografiju pod naslovom "Trsteno - Arboretum i stanica Instituta za eksperimentalno šumarstvo Jugoslavenske akademije" u kojoj su opisani njegova povijest, osnivanje, trenutno stanje i budući zadaci. Pojam i zadatak arboretuma prema Ugrenoviću (1953) "shvaćen je na način i po opsegu, kako se to čini na Zapadu, a posebice u anglo-saksonskim zemljama. U najširem značenju arboretum je ili samostalni prostor ili dio botaničkog vrta, u kojemu se drveće i grmlje uzgajaju u znanstvene, ornamentalne i uzgojne svrhe. $\mathrm{U}$ užem značenju od arboretuma se traži da ima znanstveni, ekonomski i kulturni aspekt u područjima botanike, šumarstva, poljoprivrede i hortikulture."
Tijekom vojnog napada na Dubrovačko primorje i Trsteno 2. listopada 1991. godine, kada je zapaljivom municijom izazvan požar velikih razmjera, izgorjela je sva priobalna vegetacija Dubrovačkog primorja i 80 \% površine Arboretuma. Sačuvana je samo površina povijesnih perivoja, ali također mjestimice spaljena. Tijekom vojne okupacije od 7. studenoga 1991. do 25. svibnja 1992. godine Aboretum je bio poprište ratnih aktivnosti, razaranja i pljačke. U požaru je izgorjela stara šuma alepskog bora i čempresa, makija, maslinici, rasadnik, staklenik te djelomično parteri ispred i uz ljetnikovac. Nakon napada i uništenja vegetacije požarom do daljnih šteta na kultiviranoj vegetaciji perivoja došlo je tijekom sedmomjesečne okupacije zbog povremenog nedostatka vode te odsutnosti redovnog održavanja, njege i zaštite. To se najviše odrazilo na mladim biljkama u uzgoju te je izgubljeno 48 novih svojti planiranih za obogaćenje dendrološke zbirke (Kovačević 1993, 1999). Stari i jedinstveni primjerci povijesnih nasada preživjeli su nepovoljno razdoblje, ali poneki uz trajna oštećenja.

U monografiji Ugrenović (1953) objavljeni su rezultati prvog florističkog istraživanja u Arboretumu koje je obavio akademik Ivo Pevalek u svom "Pregledu drveća, grmlja i ostalog bilja, koje se nalazi u Trstenom, prikazan po familijama” gdje navodi preko 200 vrsta, od čega 68 spontanih. Sljedeća istraživanja kultivirane i autohtone flore napravila je Kovačević u razdoblju od 1995. do 1998. godine, kada je utvrđeno 400 kultiviranih i 528 autohtonih svojti (Kovačević 1998c). Posljednja inventura postojećeg stanja zbirke kultiviranih vrsta koju su obavili Kovačević i Šimić (2007) pokazala je broj od 465 svojti vaskularnih biljaka. Taksonomskom analizom dobila se podjela na 111 porodica, 265 rodova, 377 vrsta, 6 podvrsta i 98 varijeteta, formi i kultivara. U sva tri prethodno navedena popisa svojti osim drvenastih biljaka nalaze se i trajnice, jednoljetnice i dvoljetnice. $U$ ovome radu analiza je napravljena samo za drvenaste biljke. Arboretum je ponajprije zbirka drvenastih svojti, pa je cilj ovoga rada bio prikaz i analiza drveća, grmlja i polugrmova prisutnih u Arboretumu Trsteno. Utvrđivanju sadašnjega bogatstva biljaka u Arboretumu pristupilo se radi skorašnje izrade smjernica za buduće, dugoročno gospodarenje biljkama u Arboretumu, kao i planirane izrade tiskanih materijala za turiste. Popis svojti od prije 65 godina (Ugrenović 1953) jedini je objavljen i javno dostupan popis biljaka u Arboretumu Trsteno. Popis svojti od prije 20 godina (Kovačević 1998c) je interni, nerecenzirani rukopis, a popis od prije 11 godina (Kovačević i Šimić 2007) je interna, nerecenzirana studija. Dodatni razlog inventure biljaka bila je ekstremno niska temperatura u siječnju 2017. godine koja je trajala više dana i uzrokovala smrzavanje nekih osjetljivih biljaka. Također, u Arboretumu je bilo nedeterminiranih svojti, kao i svojti za koje je trebalo ispraviti pogrešnu determinaciju. Od prethodnih popisa važeći znanstveni nazivi dijela biljaka su se promijenili, što je također trebalo uskladiti. 


\section{MATERIJAL I METODE MATERIAL AND METHODS}

\section{Područje istraživanja - Research area}

Arboretum Trsteno se nalazi u mjestu Trsteno, u Dubrovačkom primorju, $25 \mathrm{~km}$ zapadno od Dubrovnika. Prostire se na površini od 28 hektara. Proteže se u dužini od $1 \mathrm{~km}$, u smjeru istok - zapad, između mora i Jadranske turističke ceste, na obronku južne izloženosti, u rasponu nadmorskih visina od 0 do $80 \mathrm{~m}$.

Matičnu geološku podlogu čine gornjotrijaski, donjojurski i gornjokredni vodopropusni vapnenci te mjestimice vodonepropusne, klastične, gornjoeocenske flišne naslage (Herak 1991). Tektonsko obilježje terena pokazuje visoki stupanj razlomljenosti, a osnovna značajka su rasjednute bore, što području daje obilježje "ljuskave strukturne građe". Takve strukturno-tektonske značajke imaju odlučujuću ulogu u razvoju i prisutnosti hidrogeoloških pojava. Vodonepropusne klastične naslage fliša s hidrogeološkom funkcijom potpune barijere omogućile su formiranje jednog većeg, stalnog i nekoliko manjih periodičnih izvora vode (Buljan i Miklin 2004). U pedološkoj studiji Arboretuma Trsteno, Gračanin (1952) izdvaja četiri vrste tala: smeđa karbonatna tla, humizirane crvenice, crnice i apsolutno skeletna salinizirana tla.

Područje Arboretuma obilježava tipična klima sredozemnih obala, podtip po Köppenu Csa. Njena su obilježja blaga zima te vruće, suho i vedro ljeto s tri puta manjom količinom oborine u najsušem ljetnom mjesecu nego u najkišovitijem zimskom mjesecu (Penzar i Penzar 2000). U razdoblju od 1970. do 1991. godine u Arboretumu je postojala meteorološka stanica za svakodnevno motrenje meteoroloških, klimatoloških i agrometeoroloških čimbenika, kao službena postaja Državnoga hidrometerološkog zavoda u Zagrebu. Motrenje je prekinuto početkom listopada 1991. godine zbog vojnog napada i okupacije Trstenoga i šireg dubrovačkog područja, kada je meteorološka stanica potpuno uništena. Slijedom podataka dvadesetogodišnjih mjerenja, dobivene su prosječne vrijednosti i prikazane klima dijagramom (Kovačević 1998a). Srednja godišnja temperatura zraka za navedeno razdoblje iznosila je $15,5^{\circ} \mathrm{C}$, a srednja količina oborina $1284 \mathrm{~mm}$. Temperaturni srednjak za razdoblje proljeće - ljeto iznosio je $18,2{ }^{\circ} \mathrm{C}$, a pratilo ga je $482 \mathrm{~mm}$ oborina, dok je za razdoblje jesen - zima srednjak iznosio $12,7^{\circ} \mathrm{C}$ uz količinu od $811 \mathrm{~mm}$ oborina. Srednja godišnja vlažnost zraka iznosila je $67 \%$ i nije pokazivala veće razlike između toplog i hladnog razdoblja godine (Kovačević 1998a, 2012)

Biljnogeografski, Trsteno leži na južnom području eumediteranske vegetacijske zone, mediteransko-litoralnog vegetacijskog pojasa, mediteranske vegetacijske regije. Na tom se području razvija mješovita šuma hrasta crnike i crnoga jasena, Fraxino orni-Quercetum ilicis Horvatić /1956/1958
(Trinajstić 2011). Prva vegetacijska i sistematska istraživanja kultivirane i autohtone flore u Arboretumu obavila je Kovačević od 1995. do 2000. godine (HAZU 1999, 2000), a nakon kasnije revizije od 2006. do 2007. godine prikazani su rezultati u Studiji postojećeg stanja (Kovačević i Šimić 2007). Istaknuta je značajna bioraznolikost koja se očituje utvrđenom prisutnošću 9 biljnih zajednica veće pokrovnosti uz tri fragmentarno razvijene zajednice.

\section{Metode istraživanja - Research methods}

Radi utvrđivanja sadašnjega bogatstva drvenastih svojti u Arboretumu Trsteno, biljke su determinirane u razdoblju od proljeća 2017. do proljeća 2018. godine, jer je za točno određivanje pojedinih svojti bilo potrebno obuhvatiti i vegetativnu i generativnu fazu. Osim dostupnog dijela Arboretuma, tijekom terenskog rada na popisivanju biljaka vizualno su s krajnje dostupnih točaka i s ceste uz more u južnom dijelu Arboretuma, pregledani i nepristupačni dijelovi na strmim liticama na kojima uglavnom rastu autohtone biljke. Budući da je pristup tome dijelu Arboretuma opasan i zabranjen, popisane su vidljive biljke. Za potvrdu determinacije pojedinih svojti korištena je sljedeća literatura: Bärtles i Schmidt (2014), Boland i dr. (2006), Brickell (2003), Dirr (2011), Fitschen (2007), Idžojtić (2005, 2009, 2013), Krüssmann (1972, 1976), Orchard i Wilson (2001), Roloff i Bärtels (2008) i Roloff i dr. (1994-2017). Prema prikupljenim podacima napravljena je dendrološka analiza drvenastih biljaka u Arboretumu, a analizirani su sljedeći podaci: brojnost pojedinih svojti (vrsta, podvrsta, varijeteta, križanaca i kultivara), pripadnost porodici, areal, broj autohtonih svojti, broj alohtonih svojti s pojedinih kontinenata, jedinstvene ili rijetko prisutne svojte u Hrvatskoj. Iz literature su korišteni popisi drvenastih svojti prisutnih u Arboretumu Trsteno prije 65 godina (Ugrenović 1953), prije 20 godina (Kovačević 1998c) i prije 11 godina (Kovačević i Šimić 2007). Temeljem prethodnoga, učinjena je usporedba sadašnjega bogatstva dendroflore u odnosu na podatke dostupne iz sredine i kraja prošloga, kao i početka ovoga stoljeća te su navedeni neki poznati razlozi koji su doveli do razlike u brojnosti biljaka u prošlosti i danas. Za biljke koje su se u siječnju 2017. godine smrzle, ali su ipak ponovo potjerale nove stabljike, nije bilo moguće provjeriti determinaciju, već je prethodna determinacija preuzeta kao točna.

Znanstveni nazivi svojti navedeni su prema Erhardt i dr. (2014) i International Plant Names Index (IPNI), sukladno International Code of Nomenclature for algae, fungi and plants (Turland i dr. 2018). Imena autora znanstvenih naziva standardizirana su prema Brummit i Powell (1992). Nazivi kultivara navedeni su prema Hoffman (2016), sukladno International Code of Nomenclature for Cultivated Plants (Brickell i dr. 2016). Pripadnost porodici navedena je prema Cronquist (1981), Dahlgren i dr. (1985), Kramer i Green (1990) i Farjon (2010). 


\section{REZULTATI}

RESULTS

U Arboretumu Trsteno sada raste 317 drvenastih svojti, od čega je 233 vrsta, 8 podvrsta, 2 varijeteta, 10 križanaca i 64 kultivara (Tablica 1). Svojte pripadaju u 179 različitih rodova iz 82 porodice. Golosjemenjače su značajno manje zastupljene, sa samo 19 svojti, a ostalo su kritosjemenjače (298 svojti). Svojti autohtonih u Hrvatskoj je 84, što je malo više od četvrtine, a među njima prevladavaju mediteranske biljke. Od egzotičnih vrsta i podvrsta, odnosno onih koje rastu isključivo izvan europskoga kontinenta, najviše je azijskih vrsta (64), zatim slijede vrste s područja Amerike (45 vrsta), Afrike (14 vrsta) i Australije (6 vrsta). Dvije vrste rastu i u Africi i u Aziji.

Zamjetan je broj posebno vrijednih svojti, jedinstvenih ili vrlo rijetko prisutnih u Hrvatskoj, kao što su npr. Acacia cyclops A. Cunn. ex G. Don, A. karoo Hayne, Albizia amara (Roxb.) B. Boivin, Callitris preisii Miq., Casuarina cunninghamiana Miq., Persea indica (L.) Spreng., Retama sphaerocarpa Raf., Schinus weinmannifolius Engl., Vitex negundo var. heterophylla (Franch.) Rehder i dr. Arboretum se osim posebno vrijednim pojedinačnim primjercima nekih vrsta ističe i zbirkama u kojima su prisutne vrste, križanci i kultivari pojedinih rodova, kao što su zbirke različitih kultivara maslina, agruma, kultivara vinove loze, palmi, kaktusa, juka, aloja, drvenastih pelargonija i bambusa.

Ugrenović (1953) u svojoj monografiji navodi 226 drvenastih svojti tada prisutnih u Arboretumu Trsteno. Usporedbom toga popisa dendroflore od prije 65 godina i sadašnjega popisa (Tablica 1) uočljiva je razmjerno velika razlika, kako u ukupnom broju drvenastih svojti, tako u njihovom sastavu. Ukupan je broj svojti tijekom 65 godina povećan s 226 na 317. Svojti koje su se tijekom toga razdoblja do danas zadržale u Arboretumu je 148, što znači da je od današnjih 317 svojti nešto manje od pola bilo u Arboretumu i prije 65 godina. Od 226 svojti prisutnih 1953. godine danas u Arboretumu nema 74 svojte, a možemo ih podijeliti u tri skupine: 1) u nas često prisutne strane vrste: Abies cephalonica Loudon, A. concolor (Gordon et Glend.) Lindl. ex Hildebr., A. pinsapo Boiss., Acacia dealbata Link, Acer negundo L., Albizia julibrissin Durazz., Buddleja davidii Franch., Cedrus atlantica (Endl.) Manetti ex Carrière, Cryptomeria japonica (Thunb. ex L. f.) D. Don, Cunninghamia lanceolata (Lamb.) Hook., Diospyros kaki L. f., Elaeagnus angustifolia L., Ligustrum ovalifolium Hassk., Malus domestica Borkh., Morus nigra L. Musa basjoo Siebold et Zucc., Pinus brutia Ten., P. pinaster Aiton, Platycladus orientalis (L.) Franco, Populus nigra 'Italica', Prunus armeniaca L., P. avium (L.) L., P. domestica L., P. dulcis (Mill.) D.A. Webb, P. lusitanica L., Pyrus communis L., Ricinus communis L., Solanum pseudocapsicum L., Spiraea thunbergii Siebold ex Blume, Symphoricarpos albus (L.) S.F. Blake, Zi- ziphus jujuba Mill. i dr.; 2) autohtone vrste u Hrvatskoj: Arceuthobium oxycedri (DC.) M. Bieb., Capparis spinosa L., Dorycnium hirsutum (L.) Ser., Erica arborea L., Juniperus oxycedrus L., Lonicera etrusca Santi, Ruta graveolens L., Staphylea pinnata L. i Teucrium montanum L.; 3) u Hrvatskoj rijetko prisutne ili jedinstvene vrste: Acacia retinoides Schltdl., Bupleurum fruticosum L., Butia capitata (Mart.) Becc., Caesalpinia decapetala (Roth) Alston var. decapetala, Catharanthus roseus (L.) G. Don, Cephalotaxus fortunei Hook., Cinnamomum tamala (Buch.-Ham.) Nees et C.H. Eberm., Gomphocarpus fruticosus (L.) W.T. Aiton, Livistona australis (R. Br.) Mart., Phoenix sylvestris (L.) Roxb., Salvia fulgens Cav., Tecoma stans (L.) Juss. ex Kunth, Toona sinensis (A. Juss.) M. Roem., Vernicia cordata (Thunb.) Airy Shaw, V. fordii (Hemsl.) Airy Shaw i dr.

U Tablici 1 prikazana je i brojnost drvenastih svojti u Arboretumu Trsteno 1998. (Kovačević 1998c) i 2007. godine (Kovačević i Šimić 2007). U navedenim radovima popis je sadržavao i nedrvenaste bilike, koje su izostavljene u ovome radu. Kovačević (1998c) navodi 317, a Kovačević i Šimić (2007) 321 drvenastu svojtu. Prema broju svojti i njihovu popisu, vidljivo je da se većina promjena koje su nastupile u Arboretumu od 1953. godine do danas već dogodila do 1998. godine. Razlike od prije 20 i prije 11 godina do danas nisu značajne ako se gleda ukupan broj svojti, ali su dijelom zastupljene različite svojte, a te su razlike rezultat propadanja nekih biljaka iz različitih razloga, sadnje novih biljaka, a katkada i pogrešne determinacije. U odnosu na popise svojti iz 1998. i 2007. godine (tablica 1) ispravljena je pogrešna determinacija sljedećih svojti (u zagradama su navedene prethodno pogrešno determinirane svojte): Acer opalus subsp. obtusatum (Willd.) Gams (A. platanoides L.), Campsis $\times$ tagliabuana 'Mme Galen' (C. radicans (L.) Seem.), Casuarina cunninghamiana (C. equisetifolia L.), Kerria japonica 'Pleniflora' (K. japonica (L.) DC.), Pinus brutia Ten. $\times$ P. halepensis Mill. (P. brutia Ten.), Populus alba L. (P. tremula L.), Schinus weinmannifolius (S. terebinthifolia Raddi), Styphnolobium japonicum (L.) Schott (Sophora davidii (Franch.) Pavol.). Sljedeće svojte nisu bile determinirane 1998. i 2007. godine, a determinirane su 2018. godine (tablica 1): Abelia $\times$ grandiflora (Rovelli ex André) Rehder, Albizia amara, Celtis sinensis Pers., Fumana thymifolia (L.) Spach ex Webb, Lavandula lanata Boiss., Ligustrum delavayanum Har., Osmanthus fragrans (Thunb.) Lour., Phillyrea angustifolia L., Prunus persica (L.) Batsch, Pyracantha angustifolia (Franch.) C.K. Schneid., Retama sphaerocarpa, Rosa banksiae 'Alba', Salix babylonica 'Tortuosa' i Westringia fruticosa (Willd.) Druce.

Egzotične biljke toplih područja drugih kontinenata uglavnom su dobro prilagođene na stanišne uvjete u Arboretumu, međutim, povremeno stradaju od ekstremno niskih temperatura koje traju više dana, što se dogodilo u siječnju 2017. godine. Tada se na parteru ispred ljetnikovca smrznuo 
i više se nije oporavio Schinus molle L., primjerak južnoameričke vazdazelene vrste drveća, kao i eukalipti (Eucalyptus cosmophylla F. Muell. i E. sideroxylon A. Cunn. ex Woolls). Biljke porijeklom iz Australije, Afrike, Azije, Južne Amerike ili Kanarskog otočja i Madeire koje su se tada također smrzle, kasnije su potjerale nove stabljike i polako se oporavljaju su: Acacia cyclops, A. karoo, sve zasađene vrste i križanci iz roda Aloe, te Bauchinia acuminata L., Casuarina cunninghamiana, vrste i kultivari iz roda Citrus, Erythrina crista-galli L., sve svojte iz roda Pelargonium, Persea indica, Pinus canariensis C. Sm., kao i većina palmi čije se lišće smrzlo, ali se poslije razvilo novo.

Tablica 1. Popis drvenastih svojti u Arboretumu Trsteno: prije 65 godina (Ugrenović 1953), prije 20 godina (Kovačević $1998 c$ ), prije 11 godina (Kovačević i Simić 2007) i sadašnje stanje (2018. godine).

Kratice i simboli: Areal: Afr = Afrika, Az = Azija, Aus = Australija, Eu = Europa, Hr = Hrvatska, J Am = Južna Amerika, Medit $=$ Mediteran, $\mathrm{NZ}=$ Novi Zeland, Sj Am = Sjeverna Amerika, Sr Am = Srednja Amerika.

Prisutnost svojte: $\bullet=$ svojta prisutna, $-=$ svojta nije prisutna, ${ }^{*}=$ na popisu 1953., 1998. i 2007. godine svojta zabilježena pod nazivom: ${ }^{*} 1$ Acer platanoides, ${ }^{*} 2$ Bougainvillea spectabilis, ${ }^{*} 5$ Campsis radicans, ${ }^{*} 6$ Casuarina equisetifolia, ${ }^{*} 18$ Jasminum nudiflorum, ${ }^{*} 19$ Kerria japonica, *20 Ligustrum japonicum, *21 Latania lantaroides, *36 Pinus brutia, *37 Populus tremula, *38 Rosa banksiae, *39 Schinus terebinthifolia, *40 Sophora davidii, ${ }^{*} 41$ Tamarix africana, ${ }^{*} 42$ Tilia tomentosa, ${ }^{*} 43$ Viburnum opulus, ${ }^{*} 44-{ }^{*} 45$ Vitis vinifera; ${ }^{*} 4-{ }^{*} 5,{ }^{*} 7-{ }^{*} 17,{ }^{*} 22-{ }^{*} 35,{ }^{*} 46$ svojta nije bila determinirana.

Table 1 List of woody taxa in Trsteno Arboretum: 65 years ago (Ugrenović 1953), 20 years ago (Kovačević 1998c), 11 years ago (Kovačević i Šimić 2007) and the present state (2018).

Abbreviations and Symbols: Distribution: Afr $=$ Africa, $\mathrm{Az}=\mathrm{Asia}$, Aus $=$ Australia, Eu = Europe, $\mathrm{Hr}=$ Croatia, $\mathrm{J}$ Am $=$ South America, Medit $=$ Mediterranean, $\mathrm{NZ}=$ New Zealand, Sj Am = North America, Sr Am = Central America; križanac = hybrid, kultivar = cultivar.

The presence of taxa: $\bullet=$ taxon present, $-=$ taxon not present, ${ }^{*}=$ in the list 1953, 1998 and 2007 taxon recorded under the name: ${ }^{*} 1$ Acer platanoides, ${ }^{*} 2$ Bougainvillea spectabilis, ${ }^{*} 5$ Campsis radicans, ${ }^{*} 6$ Casuarina equisetifolia, ${ }^{*} 18$ Jasminum nudiflorum, ${ }^{*} 19$ Kerria japonica, *20 Ligustrum japonicum, ${ }^{*} 21$ Latania lantaroides, ${ }^{*} 36$ Pinus brutia, ${ }^{*} 37$ Populus tremula, ${ }^{*} 38$ Rosa banksiae, ${ }^{*} 39$ Schinus terebinthifolia, ${ }^{*} 40$ Sophora davidii, *41 Tamarix africana, ${ }^{*} 42$ Tilia tomentosa, ${ }^{*} 43$ Viburnum opulus, ${ }^{*} 44-{ }^{*} 45$ Vitis vinifera; ${ }^{*} 4-{ }^{*} 5,{ }^{*} 7-{ }^{*} 17,{ }^{*} 22-{ }^{*} 35,{ }^{*} 46$ taxon was not determinated.

\begin{tabular}{|c|c|c|c|c|c|}
\hline $\begin{array}{l}\text { Svojta } \\
\text { Taxon }\end{array}$ & $\begin{array}{l}\text { Areal } \\
\text { Distribution }\end{array}$ & 1953. & 1998. & 2007. & 2018 \\
\hline Abelia chinensis R. Br. & $\mathrm{Az}$ & - & $\bullet$ & $\bullet$ & - \\
\hline $\begin{array}{l}\text { Abelia } \times \text { grandiflora (Rovelli ex André) Rehder (= A. chinensis } \mathrm{R} \text {. Br. } \\
\times \text { A. uniflora } \mathrm{R} \text {. Br. ex Wall.) }\end{array}$ & $\begin{array}{l}\text { križanac } \\
\text { hybrid }\end{array}$ & - & - & - & $\bullet$ \\
\hline Abies cephalonica Loudon & $\mathrm{Eu}$ & $\bullet$ & $\bullet$ & - & - \\
\hline Abies concolor (Gordon et Glend.) Lindl. ex Hildebr. & Sj Am & $\bullet$ & - & - & - \\
\hline Abies pinsapo Boiss. & Eu & $\bullet$ & - & - & - \\
\hline Acacia cyclops A. Cunn. ex G. Don & Aus & - & $\bullet$ & $\bullet$ & $\bullet$ \\
\hline Acacia dealbata Link & Aus & $\bullet$ & $\bullet$ & - & - \\
\hline Acacia karoo Hayne & Afr & - & $\bullet$ & $\bullet$ & $\bullet$ \\
\hline Acacia retinoides Schltdl. & Aus & $\bullet$ & $\bullet$ & - & - \\
\hline Acca sellowiana (0. Berg) Burret & $\mathrm{J} \mathrm{Am}$ & - & $\bullet$ & $\bullet$ & $\bullet$ \\
\hline Acer campestre $\mathrm{L}$. & $\mathrm{Eu}, \mathrm{Az}, \mathrm{Afr}$ & $\bullet$ & $\bullet$ & $\bullet$ & $\bullet$ \\
\hline Acer monspessulanum $\mathrm{L}$. & $\mathrm{Eu}, \mathrm{Az}, \mathrm{Afr}$ & $\bullet$ & $\bullet$ & $\bullet$ & - \\
\hline Acer negundo L. & Sj Am & $\bullet$ & - & - & - \\
\hline Acer opalus subsp. obtusatum (Willd.) Gams & Eu & - & $* 1$ & $* 1$ & - \\
\hline Aesculus hippocastanum L. & Eu & $\bullet$ & $\bullet$ & $\bullet$ & $\bullet$ \\
\hline Aesculus $\times$ carnea Hayne (= A. hippocastanum L. $\times$ A. pavia L.) & $\begin{array}{l}\text { križanac } \\
\text { hybrid }\end{array}$ & - & - & $\bullet$ & $\bullet$ \\
\hline Aesculus pavia L. & Sj Am & $\bullet$ & - & - & - \\
\hline Agave americana L. & Sj Am, Meksiko & $\bullet$ & $\bullet$ & $\bullet$ & • \\
\hline Agave americana 'Marginata' & kultivar & $\bullet$ & • & $\bullet$ & • \\
\hline Agave salmiana var. ferox (K. Koch) A.H. Gentry (= A. ferox K. Koch) & Meksiko & - & $\bullet$ & $\bullet$ & - \\
\hline Agave salmiana Otto ex Salm-Dyck var. salmiana & Meksiko & - & $\bullet$ & $\bullet$ & - \\
\hline Ailanthus altissima (Mill.) Swingle & $\mathrm{Az}$ & - & $\bullet$ & - & - \\
\hline Albizia amara (Roxb.) B. Boivin & Afr, $\mathrm{Az}$ & - & - & - & $\bullet$ \\
\hline Albizia julibrissin Durazz. & $\mathrm{Az}$ & $\bullet$ & - & - & - \\
\hline Aloe arborescens Mill. & Afr & - & $\bullet$ & $\bullet$ & $\bullet$ \\
\hline
\end{tabular}




\begin{tabular}{|c|c|c|c|c|c|}
\hline $\begin{array}{l}\text { Svojta } \\
\text { Taxon }\end{array}$ & $\begin{array}{l}\text { Areal } \\
\text { Distribution }\end{array}$ & 1953. & 1998. & 2007. & 2018 \\
\hline Aloe ciliaris Haw. & Afr & - & $\bullet$ & $\bullet$ & $\bullet$ \\
\hline Aloe $\times$ delaetii Radl. (= A. ciliaris Haw. $\times$ A. succotrina Lam.) & $\begin{array}{l}\text { križanac } \\
\text { hybrid }\end{array}$ & - & - & $\bullet$ & $\bullet$ \\
\hline Aloe ferox Mill. & Afr & - & $\bullet$ & - & - \\
\hline Aloe maculata All. (= A. saponaria (Aiton) Haw.) & Afr & - & $\bullet$ & • & - \\
\hline Aloe saponaria (Aiton) Haw. $\times$ A. striata Haw. & $\begin{array}{l}\text { križanac } \\
\text { hybrid }\end{array}$ & - & $\bullet$ & - & $\bullet$ \\
\hline $\begin{array}{l}\text { Aloe } \times \text { spinosissima hort. ex Jahand. (= A. arborescens Mill. } \times A \text {. } \\
\text { humilis (L.) Mill.) }\end{array}$ & $\begin{array}{l}\text { križanac } \\
\text { hybrid }\end{array}$ & - & $\bullet$ & - & $\bullet$ \\
\hline Aloe striata Haw. & Afr & - & $\bullet$ & • & $\bullet$ \\
\hline Aloysia citriodora Paláu & $\mathrm{J} \mathrm{Am}$ & - & $\bullet$ & $\bullet$ & $\bullet$ \\
\hline Amorpha fruticosa $\mathrm{L}$. & Sj Am & - & $\bullet$ & $\bullet$ & $\bullet$ \\
\hline Ampelopsis aconitifolia Bunge & $\mathrm{Az}$ & - & $\bullet$ & $\bullet$ & $\bullet$ \\
\hline Anthyllis barba-jovis $\mathrm{L}$. & Medit & - & $\bullet$ & • & $\bullet$ \\
\hline Araucaria angustifolia (Bertol.) Kuntze & $\mathrm{J} A \mathrm{~m}$ & - & $\bullet$ & $\bullet$ & - \\
\hline Araujia sericifera Brot. & $\mathrm{J} A \mathrm{~m}$ & - & $\bullet$ & - & - \\
\hline Arbutus unedo $\mathrm{L}$. & Medit, Eu & $\bullet$ & $\bullet$ & $\bullet$ & $\bullet$ \\
\hline Arceuthobium oxycedri (DC.) M. Bieb. & $\mathrm{Eu}, \mathrm{Az}$ & $\bullet$ & - & - & - \\
\hline Argyranthemum frutescens (L.) Sch. Bip. & Kanarsko otočje & - & $\bullet$ & - & - \\
\hline Artemisia arborescens L. & Medit & - & $\bullet$ & $\bullet$ & - \\
\hline Artemisia abrotanum L. & $\mathrm{Eu}, \mathrm{Az}$ & - & $\bullet$ & - & - \\
\hline Asparagus acutifolius L. & Medit & $\bullet$ & $\bullet$ & • & $\bullet$ \\
\hline Aucuba japonica 'Variegata' & kultivar & - & $\bullet$ & $\bullet$ & $\bullet$ \\
\hline Bauchinia acuminata L. & $\mathrm{Az}$ & - & $\bullet$ & • & $\bullet$ \\
\hline Beaucarnea recurvata Lem. (= Nolina recurvata (Lem.) Hemsl.) & Sr Am & - & $\bullet$ & - & - \\
\hline Berberis julianae C.K. Schneid. & $\mathrm{Az}$ & - & $\bullet$ & $\bullet$ & $\bullet$ \\
\hline Berberis thunbergii DC. & $\mathrm{Az}$ & - & - & $\bullet$ & $\bullet$ \\
\hline Berberis thunbergii 'Atropurpurea' & kultivar & - & $\bullet$ & - & - \\
\hline Beschorneria yuccoides K. Koch & Meksiko & - & $\bullet$ & - & $\bullet$ \\
\hline Bougainvillea $\times$ buttiana 'Crimson Lake' & kultivar & - & $\bullet$ & - & - \\
\hline Bougainvillea glabra Choisy & $\mathrm{J}$ Am & $* 2$ & $\bullet$ & $\bullet$ & $\bullet$ \\
\hline Bougainvillea glabra 'Sanderiana' & kultivar & - & $\bullet$ & $\bullet$ & $\bullet$ \\
\hline Brachychiton acerifolius (A. Cunn. ex G. Don) F. Muell. & Aus & - & $\bullet$ & $\bullet$ & - \\
\hline Brachychiton populneus (Schott et Endl.) R. Br. & Aus & - & $\bullet$ & - & - \\
\hline Broussonetia papyrifera (L.) Vent. & $\mathrm{Az}$ & $\bullet$ & $\bullet$ & $\bullet$ & $\bullet$ \\
\hline Buddleja davidii Franch. & $\mathrm{Az}$ & $\bullet$ & - & $\bullet$ & - \\
\hline Bupleurum fruticosum $\mathrm{L}$. & Medit & $\bullet$ & $\bullet$ & - & - \\
\hline Butia capitata (Mart.) Becc. & $\mathrm{J} \mathrm{Am}$ & $\bullet$ & - & - & - \\
\hline Buxus balearica Lam. & Medit & - & $\bullet$ & $\bullet$ & - \\
\hline Buxus sempervirens $\mathrm{L}$. & Eu, Afr, Az & $\bullet$ & $\bullet$ & $\bullet$ & $\bullet$ \\
\hline Buxus sempervirens 'Pendula' & kultivar & $* 3$ & $\bullet$ & - & $\bullet$ \\
\hline Buxus sempervirens 'Suffruticosa' & kultivar & *4 & $\bullet$ & $\bullet$ & $\bullet$ \\
\hline Caesalpinia gilliesii (Wall. ex Hook.) Benth. & $\mathrm{J} A \mathrm{~m}$ & $\bullet$ & $\bullet$ & $\bullet$ & $\bullet$ \\
\hline $\begin{array}{l}\text { Caesalpinia decapetala (Roth) Alston var. decapetala (= C. sepiaria } \\
\text { Roxb.) }\end{array}$ & $\mathrm{Az}$ & - & - & - & - \\
\hline Calicotome spinosa subsp. villosa (Poir.) Rouy et Foucaud & Medit & - & $\bullet$ & $\bullet$ & $\bullet$ \\
\hline Callistemon citrinus (Curtis) Skeels & Aus & - & $\bullet$ & $\bullet$ & $\bullet$ \\
\hline Callitris preisii Miq. & Aus & - & • & $\bullet$ & $\bullet$ \\
\hline Calocedrus decurrens (Torr.) Florin & Sj Am & - & $\bullet$ & $\bullet$ & - \\
\hline
\end{tabular}




\begin{tabular}{|c|c|c|c|c|c|}
\hline $\begin{array}{l}\text { Svojta } \\
\text { Taxon }\end{array}$ & $\begin{array}{l}\text { Areal } \\
\text { Distribution }\end{array}$ & 1953. & 1998. & 2007. & 2018. \\
\hline Calycanthus occidentalis Hook. et Arn. & $\mathrm{Sj} A m$ & - & - & - & - \\
\hline Camellia japonica L. & $\mathrm{Az}$ & - & - & $\bullet$ & $\bullet$ \\
\hline Campsis $\times$ tagliabuana 'Mme Galen' & kultivar & *5 & *5 & $*_{5}$ & $\bullet$ \\
\hline Capparis spinosa L. & Medit, Az & $\bullet$ & - & - & - \\
\hline Carpinus orientalis Mill. & $\mathrm{Eu}, \mathrm{Az}$ & $\bullet$ & $\bullet$ & - & $\bullet$ \\
\hline Carpobrotus acinaciformis (L.) L. Bolus & Afr & - & $\bullet$ & $\bullet$ & $\bullet$ \\
\hline Carpobrotus edulis (L.) N.E. Br. & Afr & - & - & - & - \\
\hline Casuarina cunninghamiana Miq. & Aus & ${ }^{* 6}$ & ${ }^{* 6}$ & *6 & $\bullet$ \\
\hline Catharanthus roseus (L.) G. Don (= Vinca rosea L.) & Afr & - & - & - & - \\
\hline Cedrus atlantica (Endl.) Manetti ex Carrière & Afr & $\bullet$ & - & - & - \\
\hline Cedrus brevifolia (Hook. f.) A. Henry & Cipar & - & - & - & - \\
\hline Cedrus libani A. Rich. & $\mathrm{Az}$ & $\bullet$ & $\bullet$ & - & $\bullet$ \\
\hline Celastrus scandens $\mathrm{L}$. & Sj Am & $\bullet$ & - & - & - \\
\hline Celtis australis $\mathrm{L}$. & $\mathrm{Eu}, \mathrm{Afr}, \mathrm{Az}$ & - & - & - & - \\
\hline Celtis sinensis Pers. & $\mathrm{Az}$ & - & - & - & $\bullet$ \\
\hline Cephalotaxus fortunei Hook. & $\mathrm{Az}$ & $\bullet$ & - & - & - \\
\hline Ceratonia siliqua L. & Medit & $\bullet$ & $\bullet$ & $\bullet$ & $\bullet$ \\
\hline Ceratonia siliqua 'Kalabreški' (= 'Šuškavac') & kultivar & *7 & $* 7$ & - & $\bullet$ \\
\hline Ceratonia siliqua 'Šipanjac' & kultivar & *8 & *8 & - & - \\
\hline Ceratozamia mexicana Brongn. & Meksiko & - & $\bullet$ & - & - \\
\hline Cercis siliquastrum L. & Medit & $\bullet$ & $\bullet$ & $\bullet$ & $\bullet$ \\
\hline Chaenomeles japonica (Thunb.) Lindl. ex Spach & $\mathrm{Az}$ & $\bullet$ & $\bullet$ & $\bullet$ & $\bullet$ \\
\hline Chamaecyparis formosensis Matsum. & $\mathrm{Az}$ & - & $\bullet$ & - & - \\
\hline Chamaecyparis lawsoniana (A. Murray bis) Parl. & Sj Am & - & $\bullet$ & $\bullet$ & - \\
\hline Chamaerops humilis L. & Medit & - & - & - & $\bullet$ \\
\hline Chimonanthus praecox (L.) Link & $\mathrm{Az}$ & - & - & - & - \\
\hline Cinnamomum camphora (L.) J. Presl & $\mathrm{Az}$ & - & $\bullet$ & $\bullet$ & $\bullet$ \\
\hline Cinnamomum tamala (Buch.-Ham.) Nees et C.H. Eberm. & $\mathrm{Az}$ & $\bullet$ & - & - & - \\
\hline Citrus aurantium L. & $\mathrm{Az}$ & $\bullet$ & $\bullet$ & $\bullet$ & $\bullet$ \\
\hline Citrus limon 'Lisbon' & kultivar & - & $\bullet$ & $\bullet$ & - \\
\hline Citrus limon 'Mjesečar' & kultivar & - & - & $\bullet$ & $\bullet$ \\
\hline Citrus medica L. & $\mathrm{Az}$ & - & - & - & $\bullet$ \\
\hline Citrus medica 'Domaći Kalabreški' & kultivar & - & $\bullet$ & - & - \\
\hline Citrus medica 'Korsikanski' & kultivar & - & - & $\bullet$ & $\bullet$ \\
\hline Citrus nobilis Lour. & $\mathrm{Az}$ & $\bullet$ & - & - & - \\
\hline Citrus paradisi 'Duncan' & kultivar & - & $\bullet$ & $\bullet$ & $\bullet$ \\
\hline Citrus paradisi 'Natzumikan' & kultivar & - & - & - & - \\
\hline Citrus reticulata 'Clementina' & kultivar & - & $\bullet$ & $\bullet$ & $\bullet$ \\
\hline Citrus reticulata 'Havana' & kultivar & - & $\bullet$ & $\bullet$ & $\bullet$ \\
\hline Citrus sinensis (L.) Osbeck & $\mathrm{Az}$ & $\bullet$ & $\bullet$ & $\bullet$ & $\bullet$ \\
\hline Citrus sinensis 'Kuparka' & kultivar & - & $* 9$ & $\bullet$ & - \\
\hline Citrus sinensis 'Malteška' & kultivar & - & $* 10$ & $\bullet$ & - \\
\hline Citrus sinensis 'Napolitanska Crvena' & kultivar & - & $* 11$ & $\bullet$ & $\bullet$ \\
\hline Citrus sinensis 'Portugalska' & kultivar & - & $* 12$ & - & - \\
\hline Citrus sinensis 'Provansalska' & kultivar & - & $* 13$ & $\bullet$ & $\bullet$ \\
\hline Citrus sinensis 'Thompson Navel' & kultivar & - & $* 14$ & $* 14$ & $\bullet$ \\
\hline Citrus sinensis 'Washington Navel' & kultivar & - & $* 15$ & $\bullet$ & $\bullet$ \\
\hline Citrus unshiu (Swingle) Marcow & $\mathrm{Az}$ & _- & - & - & - \\
\hline
\end{tabular}




\begin{tabular}{|c|c|c|c|c|c|}
\hline $\begin{array}{l}\text { Svojta } \\
\text { Taxon }\end{array}$ & $\begin{array}{l}\text { Areal } \\
\text { Distribution }\end{array}$ & 1953. & 1998. & 2007. & 2018 \\
\hline Clematis flammula L. & Medit, Az & $\bullet$ & $\bullet$ & $\bullet$ & $\bullet$ \\
\hline Clematis vitalba L. & $\mathrm{Eu}, \mathrm{Az}$ & $\bullet$ & $\bullet$ & $\bullet$ & $\bullet$ \\
\hline Cocculus laurifolius (Roxb.) DC. & $\mathrm{Az}$ & - & $\bullet$ & $\bullet$ & $\bullet$ \\
\hline Cordyline australis (G. Forst.) Endl. & NZ & - & $\bullet$ & - & - \\
\hline Cornus mas $\mathrm{L}$. & $\mathrm{Eu}, \mathrm{Az}$ & $\bullet$ & $\bullet$ & $\bullet$ & $\bullet$ \\
\hline Cornus sanguinea L. & $\mathrm{Eu}$ & - & - & $\bullet$ & $\bullet$ \\
\hline Coronilla valentina $\mathrm{L}$. & Medit & - & $\bullet$ & $\bullet$ & $\bullet$ \\
\hline Corylus avellana L. & $\mathrm{Eu}, \mathrm{Az}$ & $\bullet$ & $\bullet$ & $\bullet$ & $\bullet$ \\
\hline Corylus maxima Mill. & $\mathrm{Eu}$ & $\bullet$ & - & - & - \\
\hline Cotinus coggygria Scop. & $\mathrm{Eu}, \mathrm{Az}$ & $\bullet$ & $\bullet$ & $\bullet$ & $\bullet$ \\
\hline Cotoneaster franchetii Bois & $\mathrm{Az}$ & - & $\bullet$ & $\bullet$ & - \\
\hline Cryptomeria japonica (Thunb. ex L. f.) D. Don & $\mathrm{Az}$ & $\bullet$ & - & - & - \\
\hline Cunninghamia lanceolata (Lamb.) Hook. & $\mathrm{Az}$ & $\bullet$ & - & - & - \\
\hline Cupressus arizonica Greene & Sj Am & - & $\bullet$ & $\bullet$ & $\bullet$ \\
\hline Cupressus goveniana Gordon ex Lindl. & Sj Am & & $\bullet$ & $\bullet$ & $\bullet$ \\
\hline Cupressus lusitanica Mill. & Meksiko, Sr Am & - & $\bullet$ & $\bullet$ & $\bullet$ \\
\hline Cupressus sempervirens L. & $\mathrm{Eu}, \mathrm{Az}, \mathrm{Afr}$ & $\bullet$ & $\bullet$ & $\bullet$ & $\bullet$ \\
\hline Cupressus torulosa D. Don ex Lamb. & $\mathrm{Az}$ & $\bullet$ & $\bullet$ & $\bullet$ & $\bullet$ \\
\hline Cycas revoluta Thunb. & $\mathrm{Az}$ & $\bullet$ & $\bullet$ & $\bullet$ & $\bullet$ \\
\hline Cydonia oblonga Mill. & $\mathrm{Az}$ & $\bullet$ & $\bullet$ & $\bullet$ & $\bullet$ \\
\hline Dasylirion longissimum Lem. & Meksiko & - & $\bullet$ & $\bullet$ & $\bullet$ \\
\hline Dasylirion serratifolium (Karw. ex Schult. et Schult. f.) Zucc. & Meksiko & $\bullet$ & $\bullet$ & $\bullet$ & $\bullet$ \\
\hline Diospyros kaki L. f. & $\mathrm{Az}$ & $\bullet$ & - & - & - \\
\hline Diospyros lotus L. & $\mathrm{Az}$ & $\bullet$ & - & - & - \\
\hline Diospyros virginiana $\mathrm{L}$. & Sj Am & $* 16$ & $\bullet$ & $\bullet$ & $\bullet$ \\
\hline Dorycnium hirsutum (L.) Ser. & Medit & $\bullet$ & - & - & - \\
\hline Dracaena draco (L.) L. & $\begin{array}{l}\text { Afr, Kanarsko } \\
\text { otočje, Madeira, } \\
\text { Zelenortski otoci }\end{array}$ & - & $\bullet$ & - & $\bullet$ \\
\hline Elaeagnus angustifolia L. & $A z$ & $\bullet$ & - & - & - \\
\hline Elaeagnus pungens Thunb. & $A z$ & - & $\bullet$ & $\bullet$ & $\bullet$ \\
\hline Elaeagnus umbellata Thunb. & $\mathrm{Az}$ & - & - & $\bullet$ & - \\
\hline Emerus major Mill. (= Coronilla emerus L.) & Eu & $\bullet$ & $\bullet$ & $\bullet$ & $\bullet$ \\
\hline Ephedra foeminea Forssk. & Medit & $\bullet$ & $\bullet$ & $\bullet$ & $\bullet$ \\
\hline Erica arborea L. & Medit, Afr & $\bullet$ & - & - & - \\
\hline Erica manipuliflora Salisb. & Medit & $\bullet$ & $\bullet$ & $\bullet$ & $\bullet$ \\
\hline Eriobotrya japonica (Thunb.) Lindl. & $\mathrm{Az}$ & $\bullet$ & $\bullet$ & $\bullet$ & $\bullet$ \\
\hline Erythrina crista-galli L. & $\mathrm{J} A \mathrm{~m}$ & - & $\bullet$ & $\bullet$ & $\bullet$ \\
\hline Eucalyptus albens Benth. & Aus & - & $\bullet$ & - & - \\
\hline Eucalyptus behriana F. Muell. & Aus & - & $\bullet$ & - & - \\
\hline Eucalyptus camaldulensis Dehnh. (= E. rostrata Schltdl.) & Aus & $\bullet$ & $\bullet$ & - & - \\
\hline Eucalyptus cosmophylla F. Muell. & Aus & - & - & $\bullet$ & - \\
\hline Eucalyptus globulus Labill. & Aus & $\bullet$ & - & - & - \\
\hline Eucalyptus sideroxylon A. Cunn. ex Woolls & Aus & - & $\bullet$ & $\bullet$ & - \\
\hline Eucalyptus sieberi L.A.S. Johnson & Aus & - & $\bullet$ & - & - \\
\hline Eucalyptus viminalis Labill. & Aus & $\bullet$ & $\bullet$ & $\bullet$ & $\bullet$ \\
\hline Euonymus japonicus Thunb. & $\mathrm{Az}$ & $\bullet$ & $\bullet$ & $\bullet$ & $\bullet$ \\
\hline
\end{tabular}




\begin{tabular}{|c|c|c|c|c|c|}
\hline $\begin{array}{l}\text { Svojta } \\
\text { Taxon }\end{array}$ & $\begin{array}{l}\text { Areal } \\
\text { Distribution }\end{array}$ & 1953. & 1998. & 2007. & 2018 \\
\hline Euonymus japonicus 'Aurea' & kultivar & - & - & $\bullet$ & $\bullet$ \\
\hline $\begin{array}{l}\text { Euphorbia characias subsp. wulfenii (Hoppe ex W.D.J. Koch) } \\
\text { Radcl.-Sm. (= E. wulfenii Hoppe ex W.D.J. Koch) }\end{array}$ & Medit & $\bullet$ & $\bullet$ & $\bullet$ & $\bullet$ \\
\hline Euphorbia dendroides $\mathrm{L}$. & Medit & $\bullet$ & $\bullet$ & $\bullet$ & $\bullet$ \\
\hline Euphorbia spinosa L. & Medit & $\bullet$ & $\bullet$ & $\bullet$ & $\bullet$ \\
\hline Fallopia baldschuanica (Regel) Holub & $A z$ & - & $\bullet$ & $\bullet$ & $\bullet$ \\
\hline Fatsia japonica (Thunb.) Decne. et Planch. & $\mathrm{Az}$ & - & $\bullet$ & $\bullet$ & $\bullet$ \\
\hline Ficus carica $\mathrm{L}$. & $\mathrm{Az}$ & $\bullet$ & $\bullet$ & $\bullet$ & $\bullet$ \\
\hline Ficus carica 'Sušelica' & kultivar & $* 17$ & $\bullet$ & $\bullet$ & - \\
\hline Ficus pumila L. & $\mathrm{Az}$ & $\bullet$ & - & - & - \\
\hline Firmiana simplex (L.) W. Wight & $\mathrm{Az}$ & - & $\bullet$ & $\bullet$ & $\bullet$ \\
\hline Fontanesia phillyreoides Labill. & $A z$ & - & $\bullet$ & $\bullet$ & - \\
\hline Forsythia suspensa (Thunb.) Vahl & $A z$ & - & $\bullet$ & $\bullet$ & - \\
\hline Forsythia viridissima Lindl. & $A z$ & $\bullet$ & - & - & - \\
\hline Fortunella japonica (Thunb.) Swingle & $\mathrm{Az}$ & - & $\bullet$ & - & - \\
\hline Fortunella margarita (Lour.) Swingle & $\mathrm{Az}$ & - & - & $\bullet$ & $\bullet$ \\
\hline Frangula rupestris (Scop.) Schur & $\mathrm{Eu}$ & $\bullet$ & $\bullet$ & $\bullet$ & $\bullet$ \\
\hline Fraxinus ornus $\mathrm{L}$. & $\mathrm{Eu}, \mathrm{Az}$ & $\bullet$ & $\bullet$ & $\bullet$ & $\bullet$ \\
\hline $\begin{array}{l}\text { Fumana ericifolia Wallr. (= F. ericoides subsp. montana (Pomel) } \\
\text { Güemes et Mun̈oz-Garm.) }\end{array}$ & Medit & $\bullet$ & $\bullet$ & - & $\bullet$ \\
\hline Fumana thymifolia (L.) Spach ex Webb & Medit & - & - & - & $\bullet$ \\
\hline Ginkgo biloba L. & $A z$ & $\bullet$ & $\bullet$ & - & - \\
\hline Gleditschia triacanthos $\mathrm{L}$. & Sj Am & $\bullet$ & $\bullet$ & - & $\bullet$ \\
\hline Gomphocarpus fruticosus (L.) W.T. Aiton (= Asclepias fruticosa L.) & Afr & $\bullet$ & $\bullet$ & - & - \\
\hline Hedera algeriensis 'Gloire de Marengo' & kultivar & - & $\bullet$ & - & - \\
\hline Hedera helix $\mathrm{L}$. & Eu, Afr, Az & $\bullet$ & $\bullet$ & $\bullet$ & $\bullet$ \\
\hline Helichrysum italicum (Roth) G. Don & Medit & $\bullet$ & $\bullet$ & $\bullet$ & $\bullet$ \\
\hline Hibiscus syriacus $\mathrm{L}$. & $\mathrm{Az}$ & $\bullet$ & $\bullet$ & $\bullet$ & $\bullet$ \\
\hline Hovenia dulcis Thunb. & $\mathrm{Az}$ & - & $\bullet$ & $\bullet$ & - \\
\hline Hydrangea macrophylla (Thunb. ex Murray) Ser. & $\mathrm{Az}$ & - & $\bullet$ & $\bullet$ & $\bullet$ \\
\hline Iberis semperflorens $\mathrm{L}$. & Medit & - & $\bullet$ & $\bullet$ & $\bullet$ \\
\hline Iberis sempervirens $\mathrm{L}$. & Medit & - & $\bullet$ & $\bullet$ & $\bullet$ \\
\hline Jacaranda mimosifolia D. Don & $\mathrm{J} A \mathrm{~m}$ & - & $\bullet$ & $\bullet$ & $\bullet$ \\
\hline Jasminum fruticans $\mathrm{L}$. & Medit, Az & $\bullet$ & - & - & - \\
\hline Jasminum humile L. & $\mathrm{Az}$ & - & $\bullet$ & $\bullet$ & $\bullet$ \\
\hline Jasminum mesnyi Hance & $\mathrm{Az}$ & $* 18$ & $\bullet$ & $\bullet$ & $\bullet$ \\
\hline Jasminum officinale L. & $\mathrm{Az}$ & $\bullet$ & $\bullet$ & - & - \\
\hline Jasminum polyanthum Franch. & $\mathrm{Az}$ & - & $\bullet$ & $\bullet$ & $\bullet$ \\
\hline Juglans regia L. & $\mathrm{Az}$ & $\bullet$ & - & $\bullet$ & $\bullet$ \\
\hline Juniperus oxcedrus subsp. macrocarpa (Sibth. et Sm.) Ball & Medit & $\bullet$ & $\bullet$ & - & - \\
\hline Juniperus oxycedrus L. subsp. oxycedrus & Medit & $\bullet$ & - & - & - \\
\hline Juniperus phoenicea L. & Medit & $\bullet$ & $\bullet$ & $\bullet$ & $\bullet$ \\
\hline Justicia brandegeana Wassh. et L.B. Sm. & Meksiko & - & $\bullet$ & $\bullet$ & $\bullet$ \\
\hline Kerria japonica 'Pleniflora' & kultivar & - & $* 19$ & $* 19$ & $\bullet$ \\
\hline Laburnum anagyroides Medik. & $\mathrm{Eu}$ & - & $\bullet$ & $\bullet$ & $\bullet$ \\
\hline Lagerstroemia indica L. & $\mathrm{Az}$ & $\bullet$ & $\bullet$ & $\bullet$ & $\bullet$ \\
\hline Lantana camara L. & Sr Am, J Am & $\bullet$ & $\bullet$ & $\bullet$ & $\bullet$ \\
\hline
\end{tabular}




\begin{tabular}{|c|c|c|c|c|c|}
\hline $\begin{array}{l}\text { Svojta } \\
\text { Taxon }\end{array}$ & $\begin{array}{l}\text { Areal } \\
\text { Distribution }\end{array}$ & 1953. & 1998. & 2007. & 2018. \\
\hline Lantana camara 'Nivea' & kultivar & - & $\bullet$ & - & - \\
\hline Lantana montevidensis (Spreng.) Briq. & $\mathrm{J} A \mathrm{~m}$ & - & $\bullet$ & $\bullet$ & $\bullet$ \\
\hline Laurus nobilis L. & Medit & - & $\bullet$ & $\bullet$ & $\bullet$ \\
\hline Lavandula angustifolia Mill. & Medit & - & $\bullet$ & $\bullet$ & $\bullet$ \\
\hline Lavandula dentata L. & Medit & - & $\bullet$ & $\bullet$ & $\bullet$ \\
\hline Lavandula lanata Boiss. & Medit & - & - & - & $\bullet$ \\
\hline Lavandula latifolia Medik. & Medit & $\bullet$ & - & - & - \\
\hline Lavatera arborea L. & $\begin{array}{l}\text { Medit, Kanarsko } \\
\text { otočje, Eu }\end{array}$ & $\bullet$ & $\bullet$ & - & $\bullet$ \\
\hline Leucaena leucocephala (Lam.) de Wit & Meksiko, Sr Am & - & $\bullet$ & $\bullet$ & - \\
\hline Ligustrum delavayanum Har. & $\mathrm{Az}$ & - & - & - & $\bullet$ \\
\hline Ligustrum lucidum W.T. Aiton & $\mathrm{Az}$ & $* 20$ & $\bullet$ & $\bullet$ & $\bullet$ \\
\hline Ligustrum ovalifolium Hassk. & $\mathrm{Az}$ & - & - & - & - \\
\hline Ligustrum vulgare L. & $\mathrm{Eu}, \mathrm{Az}, \mathrm{Afr}$ & - & $\bullet$ & - & $\bullet$ \\
\hline Liriodendron tulipifera L. & Sj Am & $\bullet$ & $\bullet$ & $\bullet$ & - \\
\hline Livistona australis (R. Br.) Mart. & Aus & - & - & - & - \\
\hline Livistona chinensis (Jacq.) R. Br. ex Mart. & $\mathrm{Az}$ & $* 21$ & $\bullet$ & $\bullet$ & $\bullet$ \\
\hline Lonicera etrusca Santi & Medit & $\bullet$ & - & - & - \\
\hline Lonicera implexa Aiton & Medit & $\bullet$ & $\bullet$ & $\bullet$ & $\bullet$ \\
\hline Lonicera maackii (Rupr.) Maxim. & $\mathrm{Az}$ & - & $\bullet$ & $\bullet$ & $\bullet$ \\
\hline Lonicera pileata Oliv. & $\mathrm{Az}$ & - & $\bullet$ & $\bullet$ & $\bullet$ \\
\hline Lycianthes rantonnetii (Carrière) Bitter & $\mathrm{J} A \mathrm{~m}$ & - & $\bullet$ & $\bullet$ & $\bullet$ \\
\hline Macfadyena unguis-cati (L.) A.H. Gentry & $\mathrm{Sr} A \mathrm{~m}, \mathrm{~J} \mathrm{Am}$ & - & $\bullet$ & - & - \\
\hline Maclura pomifera (Raf.) C.K. Schneid. & Sj Am & $\bullet$ & $\bullet$ & $\bullet$ & - \\
\hline Magnolia grandiflora L. & Sj Am & $\bullet$ & $\bullet$ & $\bullet$ & $\bullet$ \\
\hline Malus domestica Borkh. & u uzgoju & - & - & - & - \\
\hline Medicago arborea L. & Medit & - & $\bullet$ & - & - \\
\hline Melia azedarach L. & $\mathrm{Az}$ & $\bullet$ & $\bullet$ & $\bullet$ & - \\
\hline Micromeria juliana Benth. & Medit & $\bullet$ & $\bullet$ & $\bullet$ & - \\
\hline Mimosa polycarpa var. spegazzinii (Pirotta) Burkart & $\mathrm{J} A \mathrm{~m}$ & - & $\bullet$ & - & - \\
\hline Morus alba L. & $\mathrm{Az}$ & $\bullet$ & $\bullet$ & $\bullet$ & - \\
\hline Morus nigra L. & $\mathrm{Az}$ & $\bullet$ & - & - & - \\
\hline Musa basjoo Siebold et Zucc. & $\mathrm{Az}$ & $\bullet$ & - & - & - \\
\hline Musa $\times$ paradisiaca L. ( $=$ M. acuminata Colla $\times$ M. balbisiana Colla) & $\begin{array}{l}\text { križanac } \\
\text { hybrid }\end{array}$ & - & $\bullet$ & - & - \\
\hline Myrtus communis L. subsp. communis & Medit & $\bullet$ & $\bullet$ & $\bullet$ & - \\
\hline Myrtus communis subsp. tarentina (L.) Nyman & Medit & - & $\bullet$ & - & - \\
\hline Nerium oleander L. & $\mathrm{Eu}, \mathrm{Afr}, \mathrm{Az}$ & $\bullet$ & $\bullet$ & $\bullet$ & - \\
\hline Nerium oleander 'Album' & kultivar & $* 22$ & $\bullet$ & $\bullet$ & - \\
\hline Nerium oleandrum 'Album Plenum' & kultivar & $* 23$ & $\bullet$ & $\bullet$ & - \\
\hline Nerium oleandrum 'Roseum' & kultivar & $* 24$ & $\bullet$ & $\bullet$ & - \\
\hline Nerium oleandrum 'Roseum Plenum' & kultivar & $* 25$ & - & • & - \\
\hline Nerium oleandrum 'Rubrum' & kultivar & $* 26$ & $\bullet$ & $\bullet$ & $\bullet$ \\
\hline Nolina Iongifolia (Karw. ex Schult. et Schult. f.) Hemsl. & Meksiko & - & $\bullet$ & $\bullet$ & $\bullet$ \\
\hline Olea europaea L. subsp. europaea & u uzgoju & $\bullet$ & $\bullet$ & $\bullet$ & $\bullet$ \\
\hline Olea europaea subsp. sylvestris (Mill.) Rouy & Medit & - & $\bullet$ & $\bullet$ & - \\
\hline Olea europaea 'Bjelica' & kultivar & *27 & $* 27$ & $\bullet$ & - \\
\hline Olea europaea 'Brindičanka' & kultivar & $* 28$ & $* 28$ & $\bullet$ & $\bullet$ \\
\hline
\end{tabular}




\begin{tabular}{|c|c|c|c|c|c|}
\hline $\begin{array}{l}\text { Svojta } \\
\text { Taxon }\end{array}$ & $\begin{array}{l}\text { Areal } \\
\text { Distribution }\end{array}$ & 1953. & 1998. & 2007. & 2018 \\
\hline Olea europaea 'Crnica' & kultivar & - & - & $\bullet$ & $\bullet$ \\
\hline Olea europaea 'Dužica' & kultivar & - & - & $\bullet$ & $\bullet$ \\
\hline Olea europaea 'Grozdača' & kultivar & - & - & $\bullet$ & $\bullet$ \\
\hline Olea europaea 'Jeruzalemka & kultivar & - & - & $\bullet$ & $\bullet$ \\
\hline Olea europaea 'Kosmača' & kultivar & - & - & $\bullet$ & $\bullet$ \\
\hline Olea europaea 'Mezanica' & kultivar & $* 29$ & $* 29$ & $\bullet$ & $\bullet$ \\
\hline Olea europaea 'Mrčakinja' & kultivar & $* 30$ & $* 30$ & $\bullet$ & $\bullet$ \\
\hline Olea europaea 'Murgulja' & kultivar & - & - & $\bullet$ & $\bullet$ \\
\hline Olea europaea 'Oblica' & kultivar & $* 31$ & $* 31$ & $\bullet$ & $\bullet$ \\
\hline Olea europaea 'Piculja' & kultivar & *32 & $* 32$ & - & $\bullet$ \\
\hline Olea europaea 'Uljarica' & kultivar & $* 33$ & $* 33$ & $\bullet$ & $\bullet$ \\
\hline Olea europaea 'Velika Lastovka' & kultivar & - & - & $\bullet$ & $\bullet$ \\
\hline Olea europaea 'Žabarka' & kultivar & - & - & $\bullet$ & $\bullet$ \\
\hline Opuntia cylindrica (Lam.) DC. & $\mathrm{J} A \mathrm{~m}$ & - & $\bullet$ & - & - \\
\hline Opuntia ficus-indica (L.) Mill. & Meksiko & $\bullet$ & $\bullet$ & $\bullet$ & $\bullet$ \\
\hline Opuntia leucotricha DC. & Meksiko & $*_{34}$ & $\bullet$ & $\bullet$ & $\bullet$ \\
\hline Opuntia microdasys (Lehm.) Pfeiff. & Meksiko & - & $\bullet$ & - & - \\
\hline Opuntia robusta H.L. Wendl. et Pfeiff. & Meksiko & $* 35$ & $* 35$ & $\bullet$ & $\bullet$ \\
\hline Osmanthus fragrans (Thunb.) Lour. & $A z$ & $\bullet$ & - & - & $\bullet$ \\
\hline Osteospermum barberiae (Harv.) Norl. & Afr & - & - & - & $\bullet$ \\
\hline Osteospermum ecklonis (DC.) Norl. & Afr & - & $\bullet$ & $\bullet$ & $\bullet$ \\
\hline Ostrya carpinifolia Scop. & Eur, $\mathrm{Az}$ & $\bullet$ & $\bullet$ & $\bullet$ & $\bullet$ \\
\hline Osyris alba L. & Medit & $\bullet$ & $\bullet$ & $\bullet$ & $\bullet$ \\
\hline Paeonia $\times$ suffruticosa Andrews & $\begin{array}{l}\text { križanac } \\
\text { hybrid }\end{array}$ & $\bullet$ & $\bullet$ & $\bullet$ & $\bullet$ \\
\hline Paliurus spina-christi Mill. & $\mathrm{Eu}, \mathrm{Az}$ & $\bullet$ & $\bullet$ & $\bullet$ & $\bullet$ \\
\hline $\begin{array}{l}\text { Paraserianthes lopantha (Willd.) I.C. Nielsen (= Albizia lopantha } \\
\text { (Willd.) Benth.) }\end{array}$ & Aus & - & $\bullet$ & - & - \\
\hline Parthenocissus quinquefolia (L.) Planch. & Sj Am & $\bullet$ & $\bullet$ & $\bullet$ & - \\
\hline Passiflora caerulea L. & $\mathrm{Sr} A \mathrm{~m}, \mathrm{~J} \mathrm{Am}$ & $\bullet$ & $\bullet$ & $\bullet$ & $\bullet$ \\
\hline Paulownia tomentosa (Thunb.) Steud. & $\mathrm{Az}$ & $\bullet$ & $\bullet$ & $\bullet$ & $\bullet$ \\
\hline $\begin{array}{l}\text { Pelargonium } \times \text { fragrans (Poir.) Willd. (= P. exstipulatum (Cav.) L'Hér. } \\
\times \text { P. odoratissimum (L.) L'Hér.) }\end{array}$ & $\begin{array}{l}\text { križanac } \\
\text { hybrid }\end{array}$ & - & $\bullet$ & $\bullet$ & $\bullet$ \\
\hline Pelargonum grandiflorum (Andrews) Willd. & Afr & - & $\bullet$ & $\bullet$ & $\bullet$ \\
\hline Pelargonium peltatum (L.) L’Hér. & Afr & - & $\bullet$ & $\bullet$ & $\bullet$ \\
\hline Pelargonium radens H.E. Moore & Afr & - & $\bullet$ & $\bullet$ & $\bullet$ \\
\hline Pelargonium zonale (L.) L'Hér. & Afr & - & $\bullet$ & $\bullet$ & $\bullet$ \\
\hline Periploca graeca L. & Medit & - & $\bullet$ & $\bullet$ & $\bullet$ \\
\hline Persea indica (L.) Spreng. & $\begin{array}{l}\text { Kanarsko otočje, } \\
\text { Madeira }\end{array}$ & - & $\bullet$ & $\bullet$ & $\bullet$ \\
\hline Petteria ramentacea (Sieber) C. Presl & Medit & $\bullet$ & $\bullet$ & $\bullet$ & - \\
\hline Philadelphus coronarius $\mathrm{L}$. & Eu & $\bullet$ & $\bullet$ & - & - \\
\hline Phillyrea angustifolia L. & Medit & - & - & - & $\bullet$ \\
\hline Phillyrea latifolia var. media (L.) C.K. Schneid. & Medit & $\bullet$ & $\bullet$ & $\bullet$ & - \\
\hline Phlomis fruticosa $\mathrm{L}$. & Medit & $\bullet$ & $\bullet$ & $\bullet$ & $\bullet$ \\
\hline Phoenix canariensis Chabaud & Kanarsko otočje & $\bullet$ & $\bullet$ & - & $\bullet$ \\
\hline Phoenix dactylifera L. & Afr, Az & $\bullet$ & $\bullet$ & $\bullet$ & $\bullet$ \\
\hline Phoenix sylvestris (L.) Roxb. & $\mathrm{Az}$ & $\bullet$ & - & - & - \\
\hline Photinia serratifolia (Desf.) Kalkman & $\mathrm{Az}$ & $\bullet$ & $\bullet$ & $\bullet$ & $\bullet$ \\
\hline
\end{tabular}




\begin{tabular}{|c|c|c|c|c|c|}
\hline $\begin{array}{l}\text { Svojta } \\
\text { Taxon }\end{array}$ & $\begin{array}{l}\text { Areal } \\
\text { Distribution }\end{array}$ & 1953. & 1998. & 2007. & 2018 \\
\hline Phyllostachys aurea Carrière ex Rivière et C. Rivière & $\mathrm{Az}$ & $\bullet$ & $\bullet$ & $\bullet$ & $\bullet$ \\
\hline Phyllostachys nigra (Lodd. ex Lindl.) Munro & $\mathrm{Az}$ & $\bullet$ & $\bullet$ & $\bullet$ & $\bullet$ \\
\hline Phyllostachys viridiglaucescens (Carrière) Rivière et C. Rivière & $\mathrm{Az}$ & - & $\bullet$ & $\bullet$ & $\bullet$ \\
\hline Phytolacca dioica L. & $\mathrm{J} A \mathrm{~m}$ & - & $\bullet$ & - & - \\
\hline Pinus brutia Ten. & Medit & $\bullet$ & - & - & - \\
\hline Pinus brutia Ten. $\times$ P. halepensis Mill. & $\begin{array}{l}\text { križanac } \\
\text { hybrid }\end{array}$ & - & - & *36 & • \\
\hline Pinus canariensis C. Sm. & Kanarsko otočje & - & $\bullet$ & $\bullet$ & $\bullet$ \\
\hline Pinus halepensis Mill. & Medit & $\bullet$ & $\bullet$ & $\bullet$ & $\bullet$ \\
\hline Pinus nigra J.F. Arnold & $\mathrm{Eu}, \mathrm{Afr}, \mathrm{Az}$ & $\bullet$ & $\bullet$ & $\bullet$ & $\bullet$ \\
\hline Pinus pinaster Aiton & Medit & $\bullet$ & - & - & - \\
\hline Pinus pinea $\mathrm{L}$. & Medit & $\bullet$ & - & $\bullet$ & $\bullet$ \\
\hline Pistacia lentiscus L. & Medit & $\bullet$ & $\bullet$ & $\bullet$ & $\bullet$ \\
\hline Pistacia terebinthus L. & Medit & $\bullet$ & $\bullet$ & $\bullet$ & $\bullet$ \\
\hline Pistacia vera L. & $\mathrm{Az}$ & $\bullet$ & - & - & - \\
\hline Pittosporum tobira (Thunb.) W.T. Aiton & $\mathrm{Az}$ & $\bullet$ & $\bullet$ & $\bullet$ & $\bullet$ \\
\hline Pittosporum tobira 'Nana' & kultivar & - & - & $\bullet$ & $\bullet$ \\
\hline Pittosporum tobira 'Variegata' & kultivar & - & $\bullet$ & $\bullet$ & $\bullet$ \\
\hline Platanus $\times$ hispanica Münchh. (= P. occidentalis L. $\times$ P. orientalis L.) & $\begin{array}{l}\text { križanac } \\
\text { hybrid }\end{array}$ & - & $\bullet$ & $\bullet$ & $\bullet$ \\
\hline Platanus orientalis L. & $\mathrm{Eu}, \mathrm{Az}$ & $\bullet$ & $\bullet$ & $\bullet$ & $\bullet$ \\
\hline Platycladus orientalis (L.) Franco (= Thuja orientalis L.) & $\mathrm{Az}$ & $\bullet$ & $\bullet$ & - & - \\
\hline Poncirus trifoliata (L.) Raf. & $\mathrm{Az}$ & $\bullet$ & $\bullet$ & $\bullet$ & $\bullet$ \\
\hline Populus alba L. & $\mathrm{Eu}, \mathrm{Az}, \mathrm{Afr}$ & $\bullet$ & *37 & *37 & $\bullet$ \\
\hline Populus nigra L. & $\mathrm{Eu}, \mathrm{Az}, \mathrm{Afr}$ & - & $\bullet$ & - & - \\
\hline Populus nigra 'Italica' & kultivar & $\bullet$ & - & - & - \\
\hline Prasium majus L. & Medit & $\bullet$ & $\bullet$ & $\bullet$ & $\bullet$ \\
\hline Prunus armeniaca L. & $\mathrm{Az}$ & $\bullet$ & - & - & - \\
\hline Prunus avium (L.) L. & $\mathrm{Eu}, \mathrm{Az}, \mathrm{Afr}$ & $\bullet$ & - & - & - \\
\hline Prunus domestica L. & $\begin{array}{l}\text { ? križanac } \\
\text { ? hybrid }\end{array}$ & • & - & - & - \\
\hline Prunus dulcis (Mill.) D.A. Webb & $\mathrm{Az}$ & $\bullet$ & - & - & - \\
\hline Prunus laurocerasus $\mathrm{L}$. & $\mathrm{Eu}, \mathrm{Az}$ & $\bullet$ & $\bullet$ & $\bullet$ & $\bullet$ \\
\hline Prunus Iusitanica L. & Medit & $\bullet$ & - & - & - \\
\hline Prunus mahaleb $\mathrm{L}$. & $\mathrm{Eu}, \mathrm{Az}, \mathrm{Afr}$ & $\bullet$ & $\bullet$ & $\bullet$ & $\bullet$ \\
\hline Prunus persica (L.) Batsch & $\mathrm{Az}$ & $\bullet$ & - & - & $\bullet$ \\
\hline Prunus serrulata 'Kanzan' & kultivar & - & $\bullet$ & $\bullet$ & $\bullet$ \\
\hline Pseudosasa japonica (Siebold et Zucc. ex Steud.) Makino ex Nakai & $\mathrm{Az}$ & - & $\bullet$ & $\bullet$ & $\bullet$ \\
\hline Ptelea trifoliata L. & Sj Am & - & $\bullet$ & $\bullet$ & $\bullet$ \\
\hline Pueraria lobata (Willd.) Ohwi & $\mathrm{Az}$ & $\bullet$ & $\bullet$ & $\bullet$ & $\bullet$ \\
\hline Punica granatum $\mathrm{L}$. & $\mathrm{Eu}, \mathrm{Az}$ & $\bullet$ & $\bullet$ & $\bullet$ & $\bullet$ \\
\hline Punica granatum 'Legrelleae' & kultivar & - & $\bullet$ & $\bullet$ & $\bullet$ \\
\hline Putoria calabrica (L. f.) DC. & Medit & $\bullet$ & $\bullet$ & $\bullet$ & $\bullet$ \\
\hline Puya chilensis Molina & $\mathrm{J} \mathrm{Am}$ & - & $\bullet$ & $\bullet$ & - \\
\hline Pyracantha angustifolia (Franch.) C.K. Schneid. & $\mathrm{Az}$ & - & - & - & $\bullet$ \\
\hline Pyracantha coccinea M. Roem. & $\mathrm{Eu}, \mathrm{Az}$ & $\bullet$ & $\bullet$ & $\bullet$ & $\bullet$ \\
\hline Pyrus communis L. & u uzgoju & $\bullet$ & - & - & - \\
\hline Quercus faginea Lam. & Medit & - & $\bullet$ & $\bullet$ & $\bullet$ \\
\hline Quercus ilex L. & Medit & $\bullet$ & $\bullet$ & $\bullet$ & $\bullet$ \\
\hline
\end{tabular}




\begin{tabular}{|c|c|c|c|c|c|}
\hline $\begin{array}{l}\text { Svojta } \\
\text { Taxon }\end{array}$ & $\begin{array}{l}\text { Areal } \\
\text { Distribution }\end{array}$ & 1953. & 1998. & 2007. & 2018. \\
\hline Quercus pubescens Willd. & $\mathrm{Eu}, \mathrm{Az}$ & $\bullet$ & - & - & $\bullet$ \\
\hline Quercus suber L. & Medit & - & - & - & - \\
\hline Quercus trojana Webb & $\mathrm{Eu}, \mathrm{Az}$ & - & $\bullet$ & $\bullet$ & $\bullet$ \\
\hline Retama monosperma (L.) Boiss. & Medit & - & - & - & - \\
\hline Retama sphaerocarpa Raf. & Medit & - & - & - & - \\
\hline Rhamnus alaternus $\mathrm{L}$. & Medit & $\bullet$ & - & - & $\bullet$ \\
\hline Rhaphiolepis umbellata (Thunb.) Makino & $\mathrm{Az}$ & - & - & - & - \\
\hline Ricinus communis L. & Afr & - & - & - & - \\
\hline Robinia pseudoacacia L. & Sj Am & $\bullet$ & $\bullet$ & $\bullet$ & $\bullet$ \\
\hline Robinia pseudoacacia 'Unifoliola' & kultivar & - & - & - & - \\
\hline $\begin{array}{l}\text { Roldana petasitis (Sims) H.Rob. et Brettell ( = Senecio petasitis } \\
\text { (Sims) DC.) }\end{array}$ & Meksiko, Sr Am & - & - & - & $\bullet$ \\
\hline Rosa banksiae 'Alba' & kultivar & - & - & - & - \\
\hline Rosa banksiae 'Lutea' & kultivar & $* 38$ & $\bullet$ & $\bullet$ & $\bullet$ \\
\hline Rosa canina L. & $\mathrm{Eu}, \mathrm{Az}, \mathrm{Afr}$ & - & $\bullet$ & $\bullet$ & $\bullet$ \\
\hline Rosa chinensis 'Minima' & kultivar & - & - & - & - \\
\hline Rosa chinensis 'Semperflorens' & kultivar & - & $\bullet$ & $\bullet$ & $\bullet$ \\
\hline Rosa sempervirens $\mathrm{L}$. & Medit & - & - & - & - \\
\hline Rosmarinus officinalis $\mathrm{L}$. & Medit & - & - & - & - \\
\hline Rosmarinus officinalis 'Alba' & kultivar & - & - & - & - \\
\hline Rosmarinus officinalis 'Prostratus' & kultivar & - & - & $\bullet$ & $\bullet$ \\
\hline Rubus ulmifolius Schott & Eu, Medit & $\bullet$ & $\bullet$ & $\bullet$ & $\bullet$ \\
\hline Ruscus aculeatus L. & $\mathrm{Eu}, \mathrm{Az}, \mathrm{Afr}$ & $\bullet$ & $\bullet$ & $\bullet$ & $\bullet$ \\
\hline Ruscus hypoglossum L. & $\mathrm{Eu}$ & - & $\bullet$ & $\bullet$ & $\bullet$ \\
\hline Russelia equisetiformis Schltdl. et Cham. & Sr Am & - & - & - & - \\
\hline Ruta graveolens L. & Medit & $\bullet$ & - & - & - \\
\hline Sabal minor (Jacq.) Pers. & Sj Am, Meksiko & - & $\bullet$ & $\bullet$ & $\bullet$ \\
\hline Sabal uresana Trel. & Meksiko & - & $\bullet$ & $\bullet$ & $\bullet$ \\
\hline Salix babylonica L. & $\mathrm{Az}$ & $\bullet$ & - & - & - \\
\hline Salix babylonica 'Tortuosa' & kultivar & - & - & - & - \\
\hline Salvia coccinea Buc'hoz ex Etl. & Sj Am, Sr Am & - & $\bullet$ & - & $\bullet$ \\
\hline Salvia fulgens Cav. & Meksiko & $\bullet$ & - & - & - \\
\hline Salvia leucantha Sav. & Meksiko & - & $\bullet$ & - & - \\
\hline Salvia officinalis $\mathrm{L}$. & Medit & $\bullet$ & $\bullet$ & $\bullet$ & $\bullet$ \\
\hline Sambucus nigra L. & Eu, Az, Afr & - & - & - & - \\
\hline Santolina chamaecyparissus L. & Medit & $\bullet$ & $\bullet$ & $\bullet$ & $\bullet$ \\
\hline Santolina rosmarinifolia L. & Medit & - & $\bullet$ & $\bullet$ & $\bullet$ \\
\hline $\begin{array}{l}\text { Santolina } \times \text { lindavica Sünd. }(=\text { S. chamaecyparissus L. } \times \text { S. pinnata } \\
\text { subsp. neapolitana (Jord. et Fourr.) Guinea ex C. Jeffrey) }\end{array}$ & $\begin{array}{l}\text { križanac } \\
\text { hybrid }\end{array}$ & - & $\bullet$ & - & - \\
\hline Satureja montana L. & $\mathrm{Eu}, \mathrm{Az}$ & $\bullet$ & $\bullet$ & $\bullet$ & $\bullet$ \\
\hline Schinus molle L. & $\mathrm{JAm}$ & - & - & - & - \\
\hline Schinus weinmannifolius Engl. (= S. lentiscifolius Marchand) & $\mathrm{J}$ Am & - & $* 39$ & $* 39$ & $\bullet$ \\
\hline Senecio cineraria DC. & Medit & - & - & - & - \\
\hline Smilax aspera L. & Medit & $\bullet$ & $\bullet$ & $\bullet$ & $\bullet$ \\
\hline Solanum pseudocapsicum L. & Sr Am, J Am & - & - & - & - \\
\hline Sorbus domestica L. & Eu, Az, Afr & $\bullet$ & $\bullet$ & $\bullet$ & $\bullet$ \\
\hline Spartium junceum L. & Medit & $\bullet$ & $\bullet$ & - & $\bullet$ \\
\hline Spiraea cantoniensis Lour. & $\mathrm{Az}$ & - & - & $\bullet$ & $\bullet$ \\
\hline Spiraea thunbergii Siebold ex Blume & $\mathrm{Az}$ & - & - & - & - \\
\hline
\end{tabular}




\begin{tabular}{|c|c|c|c|c|c|}
\hline $\begin{array}{l}\text { Svojta } \\
\text { Taxon }\end{array}$ & $\begin{array}{l}\text { Areal } \\
\text { Distribution }\end{array}$ & 1953. & 1998. & 2007. & 2018 \\
\hline $\begin{array}{l}\text { Spiraea } \times \text { vanhouttei (Briot) Zabel }(=S \text {. cantoniensis Lour. } \times S \text {. } \\
\text { trilobata L.) }\end{array}$ & $\begin{array}{l}\text { križanac } \\
\text { hybrid }\end{array}$ & $\bullet$ & $\bullet$ & $\bullet$ & $\bullet$ \\
\hline Staphylea pinnata L. & $\mathrm{Eu}, \mathrm{Az}$ & $\bullet$ & - & - & - \\
\hline Styphnolobium japonicum (L.) Schott (= Sophora japonica L.) & $\mathrm{Az}$ & - & $* 40$ & $* 40$ & $\bullet$ \\
\hline Styrax officinalis L. & Medit & - & $\bullet$ & $\bullet$ & • \\
\hline Symphoricarpos albus (L.) S.F. Blake & Sj Am & $\bullet$ & - & - & - \\
\hline Syringa vulgaris $\mathrm{L}$. & $\mathrm{Eu}$ & $\bullet$ & $\bullet$ & $\bullet$ & $\bullet$ \\
\hline Tamarix parviflora DC. & $\mathrm{Eu}, \mathrm{Az}$ & $\bullet$ & $* 41$ & $\bullet$ & $\bullet$ \\
\hline Taxus baccata L. & $\mathrm{Eu}, \mathrm{Az}, \mathrm{Afr}$ & $\bullet$ & $\bullet$ & $\bullet$ & $\bullet$ \\
\hline Taxus baccata 'Fastigiata' & kultivar & $\bullet$ & $\bullet$ & $\bullet$ & $\bullet$ \\
\hline $\begin{array}{l}\text { Tecoma capensis (Thunb.) Lindl. (= Tecomaria capensis (Thunb.) } \\
\text { Spach) }\end{array}$ & Afr & - & - & $\bullet$ & $\bullet$ \\
\hline Tecoma stans (L.) Juss. ex Kunth & Sj Am, Sr Am, J Am & $\bullet$ & - & - & - \\
\hline Teucrium chamaedrys L. & Eu & $\bullet$ & - & $\bullet$ & $\bullet$ \\
\hline Teucrium fruticans $\mathrm{L}$. & Medit & $\bullet$ & $\bullet$ & $\bullet$ & $\bullet$ \\
\hline Teucrium montanum L. & $\mathrm{Eu}, \mathrm{Az}$ & $\bullet$ & - & - & - \\
\hline Teucrium polium L. & Medit, Az & $\bullet$ & - & $\bullet$ & $\bullet$ \\
\hline Thymbra capitata (L.) Cav. (= Coridothymus capitatus (L.) Rchb.f.) & Medit & - & $\bullet$ & - & - \\
\hline Thymus vulgaris $\mathrm{L}$. & $\mathrm{Eu}$ & $\bullet$ & $\bullet$ & $\bullet$ & $\bullet$ \\
\hline Tilia americana L. & Sj Am & $* 42$ & $\bullet$ & $\bullet$ & $\bullet$ \\
\hline Toona sinensis (A. Juss.) M. Roem. (= Cedrela sinensis A. Juss.) & $\mathrm{Az}$ & $\bullet$ & - & - & - \\
\hline Trachelospermum jasminoides (Lindl.) Lem. & $\mathrm{Az}$ & $\bullet$ & - & $\bullet$ & $\bullet$ \\
\hline Trachycarpus fortunei (Hook.) H. Wendl. & $\mathrm{Az}$ & $\bullet$ & $\bullet$ & $\bullet$ & $\bullet$ \\
\hline Ulmus minor Mill. & $\mathrm{Eu}, \mathrm{Az}, \mathrm{Afr}$ & $\bullet$ & $\bullet$ & $\bullet$ & $\bullet$ \\
\hline $\begin{array}{l}\text { Vernicia cordata (Thunb.) Airy Shaw (= Aleurites cordata (Thunb.) R. } \\
\text { Br. ex Steud.) }\end{array}$ & $\mathrm{Az}$ & $\bullet$ & $\bullet$ & - & - \\
\hline Vernicia fordii (Hemsl.) Airy Shaw (= Aleurites fordii Hemsl.) & $\mathrm{Az}$ & $\bullet$ & - & - & - \\
\hline Viburnum opulus 'Roseum' & kultivar & $* 43$ & $\bullet$ & $\bullet$ & $\bullet$ \\
\hline Viburnum tinus L. & Medit & $\bullet$ & $\bullet$ & $\bullet$ & $\bullet$ \\
\hline Vinca difformis Pourr. & Medit & - & $\bullet$ & $\bullet$ & $\bullet$ \\
\hline Vinca major L. & $\mathrm{Eu}, \mathrm{Az}$ & $\bullet$ & $\bullet$ & $\bullet$ & $\bullet$ \\
\hline Vinca major 'Variegata' & kultivar & - & $\bullet$ & $\bullet$ & $\bullet$ \\
\hline Vinca minor L. & $\mathrm{Eu}, \mathrm{Az}$ & $\bullet$ & $\bullet$ & $\bullet$ & $\bullet$ \\
\hline Vitex negundo var. heterophylla (Franch.) Rehder & $\mathrm{Az}$ & - & $\bullet$ & $\bullet$ & $\bullet$ \\
\hline Vitex agnus-castus $\mathrm{L}$. & $\mathrm{Eu}, \mathrm{Az}$ & $\bullet$ & - & $\bullet$ & $\bullet$ \\
\hline Vitis vinifera 'Amerikanica' & kultivar & - & $\bullet$ & $\bullet$ & $\bullet$ \\
\hline Vitis vinifera 'llinka' & kultivar & $* 44$ & $\bullet$ & $\bullet$ & $\bullet$ \\
\hline Vitis vinifera 'Izabela' & kultivar & - & - & $\bullet$ & $\bullet$ \\
\hline Vitis vinifera 'Lopujka' & kultivar & $* 45$ & $\bullet$ & $\bullet$ & $\bullet$ \\
\hline Vitis vinifera subsp. sylvestris (C.C. Gmel.) Hegi & $\mathrm{Eu}, \mathrm{Az}, \mathrm{Afr}$ & - & $\bullet$ & $\bullet$ & $\bullet$ \\
\hline Washingtonia filifera (Linden ex André) H. Wendl. & Sj Am & $\bullet$ & $\bullet$ & $\bullet$ & $\bullet$ \\
\hline Washingtonia robusta H. Wendl. & Sj Am & $* 46$ & $\bullet$ & $\bullet$ & $\bullet$ \\
\hline Westringia fruticosa (Willd.) Druce & Aus & - & - & - & $\bullet$ \\
\hline Wisteria sinensis (Sims) Sweet & $\mathrm{Az}$ & • & • & • & • \\
\hline Yucca aloifolia L. & Sj Am, Meksiko & - & $\bullet$ & $\bullet$ & $\bullet$ \\
\hline Yucca filamentosa $\mathrm{L}$. & Sj Am & $\bullet$ & $\bullet$ & $\bullet$ & $\bullet$ \\
\hline Yucca gloriosa L. & Sj Am & $\bullet$ & - & $\bullet$ & $\bullet$ \\
\hline Ziziphus jujuba Mill. & $\mathrm{Az}$ & $\bullet$ & - & - & - \\
\hline
\end{tabular}




\section{RASPRAVA \\ DISCUSSION}

Od 1953. godine do danas iz Arboretuma su izgubljene 74 vrste, što je vjerojatno posljedica djelovanja niza čimbenika, uključujući klimu, uvjete uzgoja, požare, ali i bolesti i štetnike. Nema točne evidencije kada je i zbog čega pojedina od tih vrsta nestala iz Arboretuma. Međutim, tijekom daljnjega razvoja Arboretuma, a posebno pri izradi smjernica za buduće dugoročno gospodarenje biljkama, treba posvetiti posebnu pozornost biljkama za koje se zna da su u prošlosti bile sastavni dio biljnoga bogatstva Arboretuma Trsteno. Treba razmotriti mogućnost da se prije unošenja novih svojti prednost da ponovnom unošenju nestalih vrsta, posebno 15 vrsta s popisa koje su u Hrvatskoj rijetko prisutne ili jedinstvene. Naravno, slijede i ostale autohtone i alohtone vrste s popisa ranije prisutnih vrsta, ali treba voditi računa o specifičnostima svake od njih, kao npr. činjenici da je negundovac invazivna vrsta u drugim dijelovima Hrvatske ili da je Acacia retinoides Schltdl. zabilježena kao invazivna vrsta u nekim mediteranskim područjima. Važno je da se posebno razmotri unošenje svake ranije prisutne ili potpuno nove vrste te da se osim potencijalnih negativnih učinaka poput invazivnosti vodi računa i o ekološkim zahtijevima. Na popisu autohtonih biljaka koje su 1953. godine zabilježene u Arboretumu, a u ostalim popisima, uključujući i 2018. godinu više nisu prisutne, nalaze se i neke česte vrste u mediteranskom području, npr. veliki vrijes, šmrika, orlovi nokti i dlakava bjeloglavica.

Povijesno vrijedan popis u kojemu je naveden dio sadnica sađenih u Perivoju Gučetić tijekom 19. stoljeća dala je Kovačević (1978). U popisu je navedeno 66 drvenastih svojti, od kojih je njih 29 i danas prisutno u Arboretumu, iako neki sadašnji primjerci tih svojti nisu primjerci iz 19. stoljeća. Za ostalih 37 biljaka s popisa, kojih danas nema u Arboretumu, nije navedeno kada i kako su nestale, a o tome nema ni drugih literaturnih podataka ili izvora u samome Arboretumu. Za te bilike također treba razmotriti mogućnost ponovnog unošenja, kao i za prethodno navedene 74 vrste s popisa Ugrenovića (1953), kojih više nema u Arboretumu.

Đurasović (1997) navodi 11 vrsta egzotičnog drveća i grmlja koje su uzgojene iz sjemena i 1994. posađene u Arboretumu. Danas su u Arboretumu od tih 11 vrsta prisutne dvije akacije: Acacia cyclops i A. karoo. Nije navedeno što je bilo s ostalim biljkama kojih danas više nema u Arboretumu, a o tome nema ni drugih pisanih podataka. Nadalje, Đurasović (1997) navodi da je krajem 1994. godine u Arboretumu Trsteno zabilježeno oko 300 vrsta egzotičnog drveća i grmlja, a u popisu navodi 97 svojti, od kojih su neke europske, odnosno pojam "egzotični" nije strogo korišten. Od tih 97 svojti danas se u Arboretumu nalazi 61 svojta.
Budući da zbog opsežnosti problematike cilj ovoga rada nije bila izrada smjernica za buduće gospodarenje biljkama u Arboretumu, već je ovaj rad neophodna podloga za definiranje tih smjernica, u radu nije naveden osvrt na biljnu komponentu Arboretuma Trsteno u budućnosti. Prioritete pri unošenju novih svojti ili ponovnom unošenju u prošlosti prisutnih svojti također treba definirati u budućim smjernicama.

U vremenskom razdoblju od prvog popisa flore do danas u Arboretum su unošene nove svojte po čemu je u brojnosti i raznolikosti sada bogatiji nego prije 65 godina. Tome je znatno pridonijelo obogaćenje zbirki pojedinih rodova, ali također i revizije prijašnjih determinacija koje su donijele na svjetlo brojne stare sorte, kao na primjer u rodova Olea, Citrus, Aloe, Pelargonium i dr. Rod Olea predstavljen je zbirkom od 15 starih autohtonih dubrovačkih sorti maslina, a rod Citrus s 10 autohtonih i 8 novijih sorti agruma, što je vrijedan doprinos očuvanju genofonda hrvatskih povijesnih autohtonih sorti.

Kovačević (1978) daje povijesni pregled unošenja i korištenja ukrasnih vrsta na područje Sredozemlja i dubrovačko područje s drugih kontinenata, ali i popis domaćih biljaka koje se sade u sredozemnim vrtovima. Autorica navodi da se u 19. stoljeću perivoj u Trstenom obogatio velikim brojem novih vrsta, koje su "definitivno izbrisale karakter njegove prvobitne koncepcije”. Sadnice su bile naručene iz rasadnika u Genovi, Milanu, Padovi, Veneciji, Grazu i Nizozemskoj, posađene u starom i novoizgrađenom dijelu perivoja, a one kojima su odgovarali životni uvjeti "danas su stabla koja čine osnovnu vrijednost biljnoga inventara Arboretuma Trsteno". Osam najstarijih živućih stabla u Arboretumu posađeno je u razdoblju od 1858. do 1871. godine (Kovačević 1998b), o čemu svjedoče arhivski zapisi i planovi sadnje: Ginkgo biloba L. (1858. godine), Tilia americana L. (1858. godine), Taxus baccata L. (1859. godine), Diospyros virginiana L. (1859. godine), Wisteria sinensis (1861. godine), Ginkgo biloba (1861. godine), Platanus orientalis L. (1868. godine) i Cedrus libani A. Rich. (1871. godine).

Dvije poznate, stare azijske platane (Platanus orientalis) u Trstenom zakonom su zaštićene od 1951. godine u kategoriji spomenika parkovne arhitekture - pojedinačno stablo i nalaze se izvan granica Arboretuma. Ugrenović (1953) ih spominje, navodeći približnu starost od 400 godina. Njihove sadašnje dimenzije (Miljas 2014) su: a) platana 1, prsni promjer $4,08 \mathrm{~m}$, visina $41 \mathrm{~m}$, promjer krošnje $45 \mathrm{~m}$; b) platana 2, prsni promjer 3,85 m, visina $33,30 \mathrm{~m}$, promjer krošnje $45 \mathrm{~m}$. Treba imati na umu da se pri spominjanju starih platana u Trstenom uvijek misli na ta dva stabla uz Jadransku magistralu, malo sjevernije od samoga Arboretuma. Azijska platana unutar granica Arboretuma posađena je 1868. godine i nalazi se malo južnije od dviju 
spomenutih starijih platana. Njen prsni promjer je 1,80 m (Kovačević i Šimić 2007). Isti autori kao najviša stabla u Arboretumu navode piramidalni čempres (Cupressus sempervirens 'Stricta') i alepski bor (Pinus halepensis Mill.), visine $36 \mathrm{~m}$, a američku lipu (Tilia americana) navode kao jedno od najvećih i najstarijih stabala, prsnog promjera 1,1 $\mathrm{m}$ i visine $35,5 \mathrm{~m}$. Ugrenović (1953) ističe i 600 godina staro stablo hrasta medunca (Quercus pubescens Willd.), koje se do 1956. godine nalazilo iza ljetnikovca, $s$ tadašnjim prsnim promjerom od $1,78 \mathrm{~m}$ i visinom od $22 \mathrm{~m}$. Osim hrasta, sva navedena stabla i sada svojom ljepotom i dimenzijama privlače pažnju posjetitelja.

Tijekom prirodne obnove vegetacije izgorjele $\mathrm{u}$ vrijeme okupacije 1991. i 1992. godine, na površinama povijesnih perivoja i njihove bliže okolice pojavilo se invazivno širenje nekoliko drvenastih vrsta: Ailanthus altissima (Mill.) Swingle, Robinia pseudoacacia L., Pueraria lobata (Willd.) Ohwi, Wisteria sinensis i Phyllostachys aurea Carrière ex Rivière et C. Rivière (Kovačević 2004). Od tada je u poslove daljnjeg održavanja Arboretuma uvršteno redovito uklanjanje mladih vegetativnih izbojaka i novih biljaka invazivnih vrsta te neprekidno nadgledanje površina.

Arboretum je s 84 drvenaste autohtone, većinom mediteranske vrste i podvrste, značajna zbirka koja čuva i predstavlja našu dendrofloru te uz ulogu u očuvanju bioraznolikosti ima važnu obrazovnu i znanstvenu ulogu za hrvatske i strane posjetitelje. Arboretum Trsteno, jedini naš primorski arboretum, jedinstven je u Hrvatskoj ne samo po bogatstvu mediteranskih i egzotičnih biljaka, već i po svojoj kulturnoj i povijesnoj vrijednosti. Ostala dva naša arboretuma, Opeka i Lisičine, kontinentalni su arboretumi te se značajno razlikuju po sastavu biljnoga fonda. Razlike se ističu i prema načinu postanka, dok su Arboretum Trsteno i Arboretum Opeka prvotno utemeljeni kao povijesni, privatni perivoji uz vile, Trsteno 1494., a Opeka 1860. godine te proglašeni arboretumima 1947./48., Arboretum Lisičine osnovan je 1979. godine sa svrhom osnivanja zbirke drvenastih biljaka s područja Europe, Azije i Amerike, kao i ukrasnih kultivara. Arboretum Opeka ima oko 180 drvenastih svojti, ali nažalost za taj arboretum nema potpunog i točnog popisa drveća i grmlja. Arboretum Lisičine, prema Idžojtić i dr. (2013), ima 512 svojti, čime je drvenastim svojtama naš najbogatiji arboretum. Za sva tri naša arboretuma treba imati na umu da su arboretumi zbirke živih, označenih drvenastih biljaka, da ponajprije imaju znanstvenu i obrazovnu funkciju i da su većinom dio znanstvenih institucija ili barem pod njihovim stručnim nadzorom. Arboretum Trsteno jedini je naš arboretum koji je pod upravom znanstvene institucije - Hrvatske akademije znanosti i umjetnosti. Prema usuglašenim međunarodnim konvencijama, organizacija Botanic Gardens Conservation International (www.bgci.org) u brojnim je dokumentima objavila smjernice i okvir za razvojnu stra- tegiju i zaštitu te direktive za osnovne zadatke suvremenog arboretuma: 1. zaštita biljnih vrsta, 2. edukacija stručnjaka i javnosti, 3. restauracija krajolika i staništa, 4. obnova vrsta koristeći metode obnove i zaštite, 5. znanstvena istraživanja, 6. promicanje botaničkih vrtova i arboretuma kao turističkih odredišta. U Akcijskom planu za botaničke vrtove u Europskoj uniji (Cheney i dr. 2000) posebno je istaknuto vođenje povijesnih arboretuma: "Povijesni arboretum mora biti tretiran kao spomenik perivojne arhitekture i on je dio europskog kulturnog nasljeđa. $U$ tom smjeru trebaju ići istraživanja i na taj način treba arboretum prezentirati posjetiteljima. Zaštita povijesne strukture mora se provoditi na dinamički način bez radikalnih promjena, strogo respektirajući povijesnu vrtnu podlogu. S botaničkoga gledišta vrt može i mora imati znanstvenu ulogu. Zbirke moraju biti birane na osnovi proučenih planova, a u skladu s tradicijom vrta te današnjim prioritetom konzervacije biološke raznolikosti." Na temelju navedenih europskih konvencija i direktiva postavljene su smjernice za razvojnu strategiju, a na temelju provedenih istraživanja Arboretuma Trsteno i dodatnih analiza (Kovačević i Šimić 2007) utvrđen je predložak prostornoga plana razvoja arboretuma (Kovačević 2012).

\section{ZAKLJUČAK} CONCLUSION

U ovome radu utvrđeno je bogatstvo drveća, grmlja i polugrmova u Arboretumu Trsteno 2018. godine, kao i razlike u brojnosti i sastavu biljaka u odnosu na sredinu i kraj prošloga te početak ovoga stoljeća. Nakon determinacije sada prisutnih drvenastih svojti, u okviru dendrološke anlize utvrđena je brojnost vrsta, podvrsta, varijeteta, križanaca i kultivara, pripadnost porodici, areal, broj autohtonih svojti, broj alohtonih svojti s pojedinih kontinenata, kao i jedinstvene ili rijetko prisutne svojte u Hrvatskoj. Determinirane su do sada nedeterminirane svojte, ispravljene dosadašnje pogreške u determinaciji, a znanstveni nazivi iz prijašnjih inventura usklađeni su s važećom nomenklaturom, kako bi usporedba i analiza bili mogući. Ovim radom napravljena je podloga za izradu smjernica za buduće, dugoročno gospodarenje biljkama u Arboretumu. Uvidom u prijašnje i sadašnje bogatstvo biljaka omogućeno je i buduće određivanje prioriteta pri unošenju novih svojti i ponovnom unošenju u prošlosti prisutnih svojti. Za biljke koje su sredinom prošloga stoljeća bile prisutne, a više ih nema u Arboretumu, uglavnom nema podataka kada su točno i zašto nestale, ali je njihov nestanak vjerojatno posljedica djelovanja niza čimbenika, uključujući klimu, uvjete uzgoja, požare, ali i bolesti i štetnike.

Arboretum Trsteno naš je najstariji arboretum, jedini u mediteranskom podneblju i jedini pod upravom neke znanstvene institucije. U Arboretumu je potrebno stalno una- 
pređivanje svih aktivnosti, poboljšano održavanje i briga o biljkama, kao i njihovo sustavno označavanje. Uz planski razvoj u budućnosti će Arboretum Trsteno i dalje biti nezaobilazno odredište turistima te još prepoznatljiviji znanstvenicima i stručnjacima zainteresiranima za našu i egzotičnu dendrofloru.

\section{LITERATURA}

\section{REFERENCES}

- Bärtles, A., P. A. Schmidt, 2014: Enzyklopädie der Gartengehölze. Verlag Eugen Ulmer, Stuttgart, 888 pp.

- Boland, D. J., M. I. H. Brooker, G. M. Chippendale, N. Hall, B. P. M. Hyland, R. D. Johnston, D. A. Kleinig, M. W. McDonald, J. D. Turner, 2006: Forest trees of Australia. CSIRO Publishing, Collingwood, 736 pp.

- Botanic Gardens Conservation International. www.bgci.org

- Brickell, C. (Ed.), 2003: RHS A-Z encyclopedia of garden plants, Vol. I-II. Dorling Kindersley, London.

- Brickell, C. D., C. Alexander, J. J. Cubey, J. C. David, M. H. A. Hoffman, A. C. Leslie, V. Malécot, W. L. A. Hetterscheid, X. Jin (Eds.), 2016: International Code of Nomenclature for Cultivated Plants (ICNCP). Ninth Edition. Scripta Horticulturae Number 18, ISHS, $190 \mathrm{pp}$.

- Brummitt, R. K., C. E. Powell, 1992: Authors of plant names. Royal Botanic Gardens, Kew, 732 pp.

- Buljan, R., Ž. Miklin, 2004: Arboretum Trsteno. Hidrološke i inženjerskogeološke značajke. Studija, Institut za geološka istraživanja, Zagreb.

- Cheney, J., J. Navarro, P. W. Jackson (Eds.), 2000: Action plan for botanic gardens in the European Union. Scripta Botanica Belgica 19: 1-68.

- Cronquist, A., 1981: An integrated system of classification of flowering plants. Columbia Univ. Press., New York, 1262 pp.

- Dahlgren, R. M. T., H. T. Clifford, P. F. Yeo, 1985: The families of monocotyledons. Structure, evolution and taxonomy. Springer Verlag, Berlin, 520 pp.

- Dirr, M. A., 2011: Dirr's encyclopedia of trees and shrubs. Timber Press, 952 pp.

- Đurasović, P., 1997: Unošenje egzotičnog drveća i grmlja na dubrovačko područje. Šumarski list 121 (5-6): 227-289.

- Erhardt, W., E. Götz, N. Bödeker, S. Seybold, 2014: Zander Handwörterbuch der Pflanzennamen. 19. Auflage. Eugen Ulmer KG, Stuttgart, $903 \mathrm{pp}$.

- Farjon, A., 2010: A handbook of the world's conifers. Vol. I-II. Brill, Leiden.

- Fitschen, J., 2007: Gehölzflora. Quelle und Meyer Verlag, Wiebelsheim, $915 \mathrm{pp}$.

- Gračanin, M., 1952: Pedološka studija Arboretuma Trsteno. Prirodoslovna istraživanja, JAZU 25: 227-267.

- HAZU, 1999: Arboretum Trsteno. Znanstvenoistraživačka djelatnost. Ljetopis HAZU za godinu 1999. Knjiga 103, Zagreb, 2000, 319 .
- HAZU, 2000: Arboretum Trsteno. Znanstvenoistraživačka djelatnost. Ljetopis HAZU za godinu 2000. Knjiga 104, Zagreb, 2001, 386.

- Herak, M., 1991: Dinaridi - Mobilistički osvrt na genezu i strukturu. Acta geologica, 21/2, Prirodoslovna istraživanja 63, Hrvatska akademija znanosti i umjetnosti, Zagreb, 35-117 pp.

- Hoffman, M. H. A., 2016: List of names of woody plants. International standard ENA 2016-2020. Naktuinbouw, Roelofarendsveen, $1080 \mathrm{pp}$.

- Idžojtić, M., 2005: Listopadno drveće i grmlje u zimskom razdoblju. Sveučilište u Zagrebu Šumarski fakultet, 256 pp.

- Idžojtić, M., 2009: Dendrologija: list. Sveučilište u Zagrebu Šumarski fakultet, 904 pp.

- Idžojtić, M., 2013: Dendrologija: cvijet, češer, plod, sjeme. Sveučilište u Zagrebu Šumarski fakultet, 672 pp.

- Idžojtić, M., I. Poljak, M. Zebec, 2013: Determinacija drveća i grmlja u Arboretumu Lisičine u okviru projekta obnove - 2 . dio. Šumarski list 137 (5-6): 325-333.

- International Plant Name Index. http://www.ipni.org./

- Kovačević, M., 1978: Pregled razvoja obogaćivanja hortikulturne flore Sredozemlja kao prijedlog obnavljanja botaničke komponente pet stoljeća starog Perivoja Gučetić. Rad JAZU, Knjiga 379, Razred za likovne umjetnosti VII: 231-237.

- Kovačević, M., 1993: Arboretum Trsteno. Ratna stradanja kulturne i prirodne baštine. Zbornik Dubrovačkog primorja i otoka IV: $145-156$

- Kovačević, M., 1998a: The significance of the spontaneous vegetation in the old garden of the Arboretum Trsteno. Acta Bot. Croat. 55/56: 29-40.

- Kovačević, M., 1998b: Nasljeđe 19. stoljeća u Gučetićevom vrtu u Arboretumu Trsteno. U: D. Grgurević (ur.), Povijesni vrtovi, perivoji i parkovi primorske Hrvatske, 161-169, Split.

- Kovačević, M., 1998c: Flora i vegetacija Arboretuma Trsteno. Rukopis.

- Kovačević, M., 1999: Prirodna obnova šume i makije na požarištima u Arboretumu Trsteno. Šumarski list 123 (3-4): $109-118$

- Kovačević, M., 2004: Invazivne vrste u Arboretumu Trsteno. U: Mitić, B. i R. Šoštarić (ur.), Prvi hrvatski botanički simpozij s međunarodnim sudjelovanjem, Zagreb, 30. 9. - 2. 10. 2004. Knjiga sažetaka. Hrvatsko botaničko društvo, 83-84, Zagreb.

- Kovačević, M. A., 2012: Perivoj Gučetićeva ljetnikovca u Trstenom - od renesansnog perivoja do Arboretuma Hrvatske akademije znanosti i umjetnosti: preobrazbe autohtonoga renesansnog predloška i njegov utjecaj na ladanjske perivoje dubrovačkog područja. Disertacija, Sveučilište u Zagrebu Arhitektonski fakultet, $486 \mathrm{pp}$.

- Kovačević, M., I. Šimić, 2007: Studija postojećeg stanja Arboretuma Hrvatske akademije znanosti i umjetnosti u Trstenom. Fond za zaštitu okoliša i energetsku učinkovitost i Hrvatska akademija znanosti i umjetnosti, Zagreb.

- Kramer, K. U., P. S. Green (Eds.), 1990: Pteridophytes and gymnosperms. U: Kubitzki, K. (Ed.), The families and genera of vascular plants. Vol I. Springer Verlag, Berlin, Heidelberg, New York, 404 pp.

- Krüssmann, G., 1972: Handbuch der Nadelgehölze. Verlag Paul Parey, Berlin und Hamburg. 366 pp. 
- Krüssmann, G., 1976: Handbuch der Laubgehölze. Band I-III. Verlag Paul Parey, Berlin und Hamburg.

- Miljas, M. (ur.), 2014: Vodič kroz zaštićene dijelove prirode u području Dubrovačko-neretvanske županije. Javna ustanova za upravljanje zaštićenim prirodnim vrijednostima na području Dubrovačko-neretvanske županije, Dubrovnik, 144 pp.

- Orchard, A. E., A. J. G. Wilson (Eds.), 2001: Flora of Australia. Vol. 11A: Mimosaceae, Acacia part 1. ABRS/CSIRO Publishing, Melbourne.

- Penzar, I., B. Penzar, 2000: Agrometeorologija. Školska knjiga, Zagreb, 153-156 pp.

- Roloff, A., A. Bärtels, 2008: Flora der Gehölze. Bestimmung, Eigenschaften und Verwendung. Eugen Ulmer KG, Stuttgart, 853 pp.

- Roloff, A., H. Weisgerber, U. M. Lang, B. Stimm (Eds.), 19942017: Enzyklopädie der Holzgewächse: Handbuch und Atlas der Dendrologie. Wiley-VCH.
- Šćitaroci, M., M. A. Kovačević, 2014: Arboretum Trsteno - perivoj renesansnoga ljetnikovca. Hrvatska akademija znanosti i umjetnosti, Art bulletin 64: 101-132.

- Trinajstić, I., 2011: Fitogeografska raščlanjenost biljnog pokrova. U: S. Matić (ur.), Šume hrvatskoga Sredozemlja, Akademija šumarskih znanosti, Zagreb, 182-187 pp.

- Turland, N. J., J. H. Wiersema, F. R. Barrie, W. Greuter, D. L. Hawksworth, P. S. Herendeen, S. Knapp, W.-H. Kusber, D.-Z. Li, K. Marhold, T. W. May, J. McNeill, A. M. Monro, J. Prado, M. J. Price, G. F. Smith (Eds.), 2018: International Code of Nomenclature for algae, fungi, and plants (Shenzhen Code) adopted by the Nineteenth International Botanical Congress Shenzhen, China, July 2017. Regnum Vegetabile 159. Glashütten: Koeltz Botanical Books. https://www.iapt-taxon.org/nomen/main.php./

- Ugrenović, A., 1953: Trsteno - Arboretum i stanica Instituta za eksperimentalno šumarstvo Jugoslavenske akademije. Jugoslavenska akademija znanosti i umjetnosti, Zagreb, 215 pp.

\section{SUMMARY}

The Trsteno Arboretum, managed by the Croatian Academy of Sciences and Arts, is a former land estate with gardens, old olive groves and natural vegetation. It is a protected site of natural and cultural goods of the Republic of Croatia. The history of its land estate can be traced back to the year 1494, while the Arboretum itself was established in 1948 over 28 ha. It has been 65 years since the first list of plants in the Arboretum was drawn up. In order to determine the current wealth of woody taxa, the plants were documented during 2017 and 2018. A dendrological analysis was made and the present richness of the woody plants was compared to the literary data from the middle and the end of the 20th century and the beginning of the 21st century. Currently, the Arboretum contains 317 woody taxa, of which 233 are species, 8 subspecies, 2 varieties, 10 hybrids and 64 cultivars (Table 1). The taxa belong to 179 different genera from 82 families. The gymnosperms are considerably less represented with 19 taxa, and the rest are angiosperms (298 taxa). Slightly more than a quarter of the species and subspecies are autochthonous in Croatia and are predominantly Mediterranean species. The Trsteno Arboretum is the only littoral arboretum in Croatia which supports important collections that preserve and represent the Croatian dendroflora. As a guardian of biodiversity, the Arboretum has an important educational and scientific role for both Croatian and foreign visitors. The majority of the exotic species and subspecies, that is, those which occur exclusively outside the European continent, are of Asian origin (64 species), followed by the species from the area of America (45 species), Africa (14 species) and Australia (6 species). There is a large number of particularly valuable taxa that are unique to or rarely present in Croatia, such as Acacia cyclops A. Cunn. ex G. Don, A. karoo Hayne, Albizia amara (Roxb.) B. Boivin, Callitris preisii Miq., Casuarina cunninghamiana Miq., Persea indica (L.) Spreng., Retama sphaerocarpa Raf., Schinus weinmannifolius Engl. and Vitex negundo var. heterophylla (Franch.) Rehder. Besides the particularly valuable individual examples of some species, the Arboretum also boasts collections that include species, hybrids and cultivars of various genera. Since the first plant list was drawn up, new taxa have continuously been introduced into the Arboretum, making it wealthier and more diverse in species than 65 years ago. This was achieved by enriching the collections of particular genera, but also by revising previous documentation, which brought to light numerous old cultivars, such as those in the genera Olea, Citrus, Aloe, Pelargonium and others. The genus Olea is represented by a collection of 15 old autochthonous olive cultivars from the area of Dubrovnik, and the genus Citrus with 10 autochthonous and 8 more recent citrus cultivars. This is a valuable contribution to the preservation of the genofund of historical autochthonous Croatian cultivars. Over the past 65 years, the total number of taxa has increased from 226 to 317. The number of taxa which have survived in the Arboretum until the present day is 148, meaning that of the present 317 taxa, slightly less than half were in the Arboretum 65 years ago. Of the 226 taxa present in 1953, 74 taxa have disappeared from the Arboretum as a result of a number of different factors, including the climate, growing conditions, fires, but also diseases and pests. The majority of the changes occurring 
in the Arboretum since 1953 took place before 1998. For future maintenance and development of the Arboretum in the sense of regenerating the taxa that have disappeared or introducing new taxa, the facts mentioned above should be of particular concern. Exotic plants from warm regions of other continents are generally well adapted to the site conditions in the Arboretum, but they sometimes perish owing to extremely low temperatures lasting for several days. The eight oldest living trees in the Arboretum were planted in the period between 1858 and 1871: Ginkgo biloba L. (1858), Tilia americana L. (1858), Taxus baccata L. (1859), Diospyros virginiana L. (1859), Wisteria sinensis (Sims) Sweet (1861), Ginkgo biloba L. (1861), Platanus orientalis L. (1868) and Cedrus libani A. Rich. (1871). The Trsteno Arboretum is the only Croatian arboretum that is managed by a scientific institution - the Croatian Academy of Sciences and Arts, and it fulfils all the requirements set before a historical arboretum in the modern world.

KEY WORDS: Trsteno Arboretum, Croatia, Mediterranean, trees, shrubs, half-shrubs, dendrological analysis 